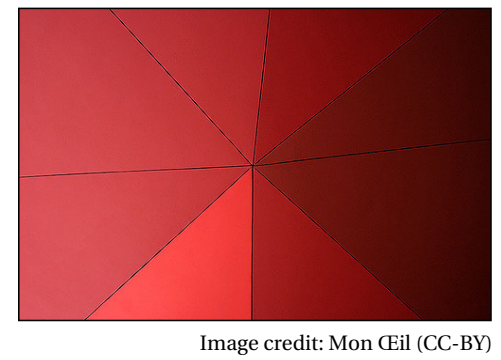

Innovation Strategy and Practice

Welcome to the November issue of the Technology

Innovation Management Review. We welcome your

comments on the articles in this issue as well as

suggestions for future article topics and issue themes.

Editorial: Innovation Strategy and Practice Chris McPhee

Collaboration Strategies in Innovation Ecosystems: An Empirical

Study of the German Microelectronics and Photonics Industries Fabian Schroth and Johann Jakob Häußermann

A Strategic Management Maturity Model for Innovation

Ferhat Demir

A Practice Method for Studying Creative Communities

Pekka Buttler

Information Security Best Practices: First Steps for Startups and SMEs Urpo Kaila and Linus Nyman

Author Guidelines 


\section{Publisher}

The Technology Innovation Management Review is a monthly publication of the Talent First Network.

\section{ISSN}

1927-0321

\section{Editor-in-Chief}

Chris McPhee

\section{Advisory Board}

Tony Bailetti, Carleton University, Canada

Peter Carbone, Ottawa, Canada

Parm Gill, Gill Group, Canada

Leslie Hawthorn, Red Hat, United States

Michael Weiss, Carleton University, Canada

\section{Review Board}

Tony Bailetti, Carleton University, Canada

Peter Carbone, Ottawa, Canada

Parm Gill, Gill Group, Canada

G R Gangadharan, IBM, India

Mohammad Saud Khan, Victoria University of

Wellington, New Zealand

Seppo Leminen, Pellervo Economic Research and Aalto University, Finland

Colin Mason, University of Glasgow, United Kingdom

Steven Muegge, Carleton University, Canada

Jennifer Percival, University of Massachusetts, United States

Risto Rajala, Aalto University, Finland

Punit Saurabh, Nirma University, India

Sandra Schillo, University of Ottawa, Canada

Marina Solesvik, Nord University, Norway

Stoyan Tanev, Carleton University, Canada

Michael Weiss, Carleton University, Canada

Mika Westerlund, Carleton University, Canada

Blair Winsor, Memorial University, Canada

(C) $2007-2018$

Talent First Network

www.timreview.ca

\section{Overview}

The Technology Innovation Management Review (TIM Review) provides insights about the issues and emerging trends relevant to launching and growing technology businesses. The TIM Review focuses on the theories, strategies, and tools that help small and large technology companies succeed.

Our readers are looking for practical ideas they can apply within their own organizations. The TIM Review brings together diverse viewpoints - from academics, entrepreneurs, companies of all sizes, the public sector, the community sector, and others - to bridge the gap between theory and practice. In particular, we focus on the topics of technology and global entrepreneurship in small and large companies.

We welcome input from readers into upcoming themes. Please visit timreview.ca to suggest themes and nominate authors and guest editors.

\section{Contribute}

Contribute to the TIM Review in the following ways:

- Read and comment on articles.

- Review the upcoming themes and tell us what topics you would like to see covered.

- Write an article for a future issue; see the author guidelines and editorial process for details.

- Recommend colleagues as authors or guest editors.

- Give feedback on the website or any other aspect of this publication.

- Sponsor or advertise in the TIM Review.

- Tell a friend or colleague about the TIM Review.

Please contact the Editor if you have any questions or comments: timreview.ca/contact

\section{About TIM}

The TIM Review has international contributors and readers, and it is published in association with the Technology Innovation Management program (TIM; timprogram.ca), an international graduate program at Carleton University in Ottawa, Canada. 


\section{Editorial: Innovation Strategy and Practice Chris McPhee, Editor-in-Chief}

Welcome to the November 2018 issue of the Technology Innovation Management Review. This month's editorial theme is Innovation in Practice. The authors in this issue share insights on strategies for collaborating in innovation ecosystems, assessing strategic maturity for innovation, the practice of studying creative communities, and implementing best practices for cybersecurity.

In the first article, Fabian Schroth and Johann Jakob Häußermann from the Fraunhofer Center for Responsible Research and Innovation at Fraunhofer IAO in Berlin, Germany, examine the extent to which companies develop different and new strategies for collaborating with research institutions within innovation ecosystems. Their findings identify two ideal types of collaboration strategies, and they discuss the practical implications of these strategies for managers seeking to collaborate in such systems.

Next, Ferhat Demir, management lecturer, trainer, and consultant, presents a new conceptual model for assessing the maturity of strategic management in any organization. The Strategic Management Maturity Model for Innovation (S3M-i) is composed of six maturity levels with seven dimensions, and it is designed to align innovation with business strategies. The article introduces the model and provides guidance for putting it into practice in assessing a company's strategic management maturity level for innovation.

Then, Pekka Buttler from the Hanken School of Economics in Helsinki, Finland, introduces the Practice Method for Studying Creative Communities (PMSCC). This real-time method focuses on the micro-interactions through which organizations generate ideas and therefore offers practitioners and researchers an opportunity to gain new insights into an otherwise relatively opaque process. The article present results from a research project utilizing the PMSCC to illustrate how the method can produce worthwhile findings, foster new insights, and help practitioners hone their creative processes.
Finally, Urpo Kaila from the Finnish IT Center for Science (CSC) and Linus Nyman from the Hanken School of Economics in Helsinki, Finland, share information security best practices for startups and SMEs. The article provides a lightweight yet comprehensive security framework for owners or managers of small companies who have not yet implemented security-related practices. It also serves as a general introduction to the topic for readers seeking a general understanding of security best practices and their implementation.

For future issues, we are accepting general submissions of articles on technology entrepreneurship, innovation management, and other topics relevant to launching and growing technology companies and solving practical problems in emerging domains. Please contact us (timreview.ca/contact) with potential article topics and submissions.

\section{Chris McPhee \\ Editor-in-Chief}

\begin{abstract}
About the Editor
Chris McPhee is Editor-in-Chief of the Technology Innovation Management Review. Chris holds an MASc degree in Technology Innovation Management from Carleton University in Ottawa, Canada, and $\mathrm{BScH}$ and MSc degrees in Biology from Queen's University in Kingston, Canada. He has nearly 20 years of management, design, and content-development experience in Canada and Scotland, primarily in the science, health, and education sectors. As an advisor and editor, he helps entrepreneurs, executives, and researchers develop and express their ideas.
\end{abstract}

Citation: McPhee, C. 2018. Editorial: Innovation

Strategy and Practice. Technology Innovation

(cc) BY

Management Review, 8(11): 3-3.

http://doi.org/10.22215/timreview/1194

Keywords: innovation, creativity, practice, research, framework, model, method, strategy, innovation ecosystems, collaboration, research institutions, maturity model, information security, cybersecurity, best practice 


\title{
Collaboration Strategies in Innovation Ecosystems: An Empirical Study of the German Microelectronics and Photonics Industries
}

\author{
Fabian Schroth and Johann Jakob Häußermann
}

\author{
"As great ideas can be discovered in diverse and") \\ unexpected places, we need to collaborate in new \\ and surprising ways.
}

\author{
Tom Hulme \\ Founder of OpenIDEO
}

\begin{abstract}
Effective collaboration between companies and research organizations is key to successful innovation systems. Against the background of digitalization, a shift from traditional innovation systems towards innovation ecosystems can be observed. In this article, we investigate how companies operating in innovation ecosystems address the challenge of collaboration in dynamic innovation ecosystems. We focus on microelectronics and photonics in Germany as examples of knowledge- and research-intensive industries and analyze the strategies of companies to collaborate with research organizations. We explore whether and to what extent companies develop different and new strategies for collaborating with research institutions within innovation ecosystems, on the basis of which we identify two ideal types of strategies. Whereas ideal type A is aiming towards obtaining specific knowledge in order to further develop a particular technology or product (i.e., towards incremental innovation), ideal type B seeks to harness the new and full potential of innovation ecosystems (i.e., aiming at rather radical innovation). Finally, our findings contribute to a better understanding of innovation ecosystems and give managerial implications for collaborating in such systems.
\end{abstract}

\section{Introduction}

The development of new technologies is extremely knowledge-intensive and entails new challenges, particularly with respect to the generation and diffusion of knowledge: it is becoming highly dynamic and characterized by intensive collaboration. For companies involved in innovation ecosystems (Adner \& Kapoor, 2010; Autio \& Thomas, 2014; Jackson, 2011; Valkokari, 2015), this implies that they can no longer develop new technologies - much less new products and services on their own, but instead need to cooperate with external organizations, including research institutes and other companies (Pellikka \& Ali-Vehmas, 2016). This is particularly true for companies in knowledge-intensive industries that have seen an increase in external collaboration for creating and commercializing innovation (Dolata, 2016; Siikonen et al., 2011).
Digitalization is creating new ways of exchanging information and completely new approaches to innovation processes - both within companies and at the interface to research institutions or end customers. The resulting challenges and opportunities for innovation affect all sectors, but in particular all knowledge-intensive industries. Here, collaboration intensifies, and we observe the emergence of innovation ecosystems as dynamic and co-productive spaces for research, development, and innovation (R\&D\&I) activities characterized by a high interdependence of industry and research actors (Adner \& Kapoor, 2010; Autio \& Thomas, 2014).

Both photonics and microelectronics are knowledge-intensive industries. These companies spend about $10 \%$ of their revenue on research and development, which is far above the average of approximately $4 \%$ across the manufacturing industry (VDI, 2016). Both industries 


\section{Collaboration Strategies in Innovation Ecosystems: An Empirical Study of the German Microelectronics and Photonics Industries Fabian Schroth and Johann Jakob Häußermann}

provide key enabling technologies for digitalization and are increasingly affected by it. Companies in these industries engage in collaborative $R \& D$ with other actors in their supply and value chain (Häußermann et al., 2018). With photonics, a research-intensive industry has been selected that makes a significant contribution to the competitiveness of German companies. With an export quota of almost $70 \%$, photonics is one of the most export-oriented sectors of the German economy. The photonics industry employs 130,000 people in Germany with a turnover of $€ 31.5$ billion $(\sim \$ 47$ billion CAD). Of the approximately 1,000 total companies, about $85 \%$ are small and medium-sized enterprises (Spectaris, 2010, 2014). With microelectronics, a sector of the capital goods industry has been selected that serves as an important enabler in the business-to-business (B2B) sector and comprises a large number of large companies. As an approximation for evaluating the significance of microelectronics, data from the German electrical industry can be consulted. According to this, the industry generated sales of $€ 176$ billion ( $\$ 260$ billion CAD) in 2016 and employed 849,000 people (ZVEI, 2017).

This article is structured as follows. First, we review the existing literature on innovation ecosystems, concentrating in particular on the need for companies to collaborate in interdependent and dynamic innovation ecosystems. Next, we provide a short overview of our methodological approach. This is followed by a description of our empirical findings, wherein we identify and analyze factors that motivate companies to seek the collaboration of research institutions, their criteria for choosing potential collaborators, common modes of collaboration, and lastly, factors that promote or prevent collaboration. In the fourth part of the article, we present two ideal types of strategies companies employ to deal with the challenges of collaboration within innovation ecosystems. Finally, we discuss our findings within the theoretical context of innovation ecosystems and give managerial implications.

\section{Collaboration of Knowledge and Business Actors in Innovation Ecosystems}

Since the early 1990s, innovation studies have focused on knowledge as the central resource for innovation and learning among diverse actors as the central process (Lundvall, 2010). Contrasting earlier conceptions of linear innovation processes, the perspective has changed toward a system perspective of innovations, which takes into account the interaction of diverse actors and the systems of knowledge production and diffusion. From this perspective, the dynamics of the relationships in such systems are of interest as well as different types of knowledge leading to specific characteristics of these systems (Asheim \& Coenen, 2005). Studies focus on the capacity of companies to search and learn in such systems (Lundvall, 2007) as well as on the dynamics among different innovation stakeholders - namely industry, academia, the state, and civil society - in innovation systems (Carayannis \& Campbell, 2009). In the interaction of the innovation helices, overlays of communications, networks, and organizations may appear (Etzkowitz \& Leydesdorff, 2000).

In recent years, the term "innovation ecosystem" has gained prominence in innovation studies as a way to describe one such overlay: the dynamic and co-productive space in which industrial R\&D\&I takes place. The term highlights both interdependencies between organizations and the co-evolution of value (Adner \& Kapoor, 2010; Autio \& Thomas, 2014). Within innovation ecosystems, companies do not innovate individually, but rather depend on the resources and know-how of other organizations (Adner \& Kapoor, 2010). In contrast to other concepts, such as clusters and innovation systems, this notion encapsulates a wide range of organizations, institutions, and actors in the value chain, both upstream and downstream. Innovation ecosystems are not confined to a single industry either; instead, they form around a specific application or innovation and thus consist not only of companies but also include other actors that contribute to the innovation process as a whole, from exploration to exploitation. This includes investors, marketing agencies, and even knowledge providers - any and all actors, in fact, "that [specialize] in the development, discovery, delivery, and deployment of evolving applications" (Autio \& Thomas, 2014).

Most existing studies focus on single companies so as to describe and analyze what we would consider business ecosystems, in other words, they focus on those concerned with value creation (Valkokari, 2015). However, by focusing on single companies and the value-creation process, these studies leave aside collaboration in innovation systems. Collaboration entails two central elements: interactive learning and the creation of new knowledge (Asheim \& Coenen, 2005; Lundvall, 2007). Although interactive learning is a process based on learning by doing and using, and thus, it aims at incremental innovations, knowledge creation refers to activities that aim at radical innovations. As innovation ecosystems overlap highly dynamic spheres of innovation (Etzkowitz \& Leydesdorff, 2000), the development of collaborative processes for learning and creating knowledge poses particular challenges to the innovation actors. 


\section{Collaboration Strategies in Innovation Ecosystems: An Empirical Study of the German Microelectronics and Photonics Industries Fabian Schroth and Johann Jakob Häußermann}

Against this backdrop, we ask how companies collaborate with research organizations in innovation ecosystems to gain access to external knowledge and thus to create and transfer knowledge for innovation. Innovation ecosystems result from reflective activities of interdependent innovation actors (Etzkowitz \& Leydesdorff, $2000)$. We assume that collaboration for innovation also results from such reflective processes. Thus, we analyze the strategies companies deploy in two innovation ecosystems, namely the German microelectronics and photonics ecosystems, to deal with the challenge of collaboration in dynamic innovation ecosystems. To this end, we identify the factors that motivate companies to seek collaboration with research institutions, we look at how said collaboration is usually initiated, we examine common types and means of collaboration, and finally, we identify both success factors and barriers to collaboration - thus contributing empirical insights into the collaboration strategies in innovation ecosystems.

\section{Method}

In addressing our research questions, we analyzed how companies interact with research organizations which we take to be the relevant knowledge providers in innovation ecosystems - during collaborative R\&D\&I. We conducted a total of 42 qualitative interviews comprising 36 interviews with senior management from the research, strategy, and product management departments of both SMEs and large companies, and 6 interviews with representatives of interest groups and cluster organizations. The interviews each lasted between one and two hours. We analyzed the interviews using both in vivo codes and a codebook in order to distinguish ideal types (Weber, 1904) of the collaboration strategies companies deploy in innovation ecosystems. By deriving ideal types from our empirical findings, we were able to identify and highlight certain significant trends in our data.

When analyzing the interviews, we became aware that there were no significant differences relevant to our research interests between photonics and microelectronics. This is due in part to the technological proximity of the two industries, meaning that companies from photonics regularly work with companies from microelectronics, and vice versa. Secondly, both photonics and microelectronics are research-intensive industries in which close collaboration with research organizations plays a central role. Accordingly, we did not differentiate between the two industries in our subsequent analysis, interpretation, and presentation of the data.

\section{Empirical Findings}

In order to understand the challenges companies face in dealing with research organizations, we analyzed why, how, and with whom companies collaborate. Together, these observations provide a clearer understanding of how companies collaborate with research organizations, so as to exchange, create, and transfer knowledge for innovation in dynamic ecosystems.

\section{Motivating factors}

In this section, we describe the reasons respondents cited for engaging in collaboration with research organizations. This helps reveal the underlying incentive structures for collaboration. Respondents identified the following motivating factors:

1. Environment and market: As both industries are continually evolving through technical innovation, companies are constantly confronted with new challenges. Through collaboration with research institutions, it is possible to integrate external (predominantly technological) expertise, either on a one-off or short-term basis at specific stages of the innovation process, or via long-term collaboration.

2. Outsourcing of research: Although microelectronics and photonics are research-intensive industries, many SMEs in particular outsource their basic research to publicly funded research institutions. In addition, the participation of research institutions is sought when specific external technological expertise is required.

"Why do I collaborate with others? Because I want a specialist and because the specialist can do it faster and more safely than I can do it myself." (Company representative)

3. Complementary competences and infrastructures: Through collaboration with research organizations, new competencies can be jointly developed for the generation of intellectual property (IP) - which companies can in turn use both to secure their market position and gain access to new markets. Furthermore, collaboration entails access to the infrastructure of partner organizations: thus, companies in the photonics industry, for example, regularly use the facilities and equipment of research organizations.

4. Networking: In addition to the primary benefit of access to new knowledge and technologies, collaboration 


\section{Collaboration Strategies in Innovation Ecosystems: An Empirical Study of the German Microelectronics and Photonics Industries Fabian Schroth and Johann Jakob Häußermann}

with research organizations also holds significant secondary benefits for companies. Said collaboration can help companies expand their professional networks and gain access to potential customers. Companies can also capitalize on their association with academic establishments for marketing purposes. Secondary benefits furthermore include access to potential future employees.

\begin{abstract}
"One could also call it indirect recruiting, because these projects naturally provide access to graduates or PhD students who then get to know our development, our work, our working environment, get to know us personally, and then say: 'Oh, that would be something for me.' So the collaborative projects have multiple benefits." (Large corporation in the photonics industry)
\end{abstract}

To summarize, the above analysis reveals different reasons for companies to collaborate with research organizations. While some companies seek access to the knowledge, skills, and infrastructure they themselves lack, others are motivated by opportunities to network and reap the benefits of a functioning innovation ecosystem (Pellikka \& Ali-Vehmas, 2016). These differing motivations are indicative of different collaboration strategies, and hence diverging perspectives on innovation ecosystems.

\section{Prerequisites for collaboration}

The next step in our research was to examine how companies identify potential collaborators. Our study revealed three relevant sets of criteria for collaboration with a particular research establishment:

1. Sufficient academic and technical expertise: Companies look for research institutions that can provide the technical know-how they need, possess the necessary technological infrastructure, and conduct research work of a high standard - as evidenced by their contributions to academic conferences and publications, for example.

2. Favourable terms and conditions: This includes both the basic legal terms and conditions, in particular with respect to IP rights and non-disclosure agreements - which can contribute to the failure of newly established or emerging partnerships - and factors such as time frames, the possibility of recruiting employees, and conditions that allow for the bilateral exchange of complementary knowledge and skills without the risk of direct competition with the partner organization.
3. Social criteria: Though less tangible and harder to measure than the above two sets of criteria, companies strongly emphasize the importance of social factors. In particular, trust is described as the most important criterion for identifying potential partners.

"Personal contacts play an important role here. Especially when the involved parties have been around longer, they usually have a shared history, know each other well, and so on. There is no denying that this also plays a very big role." (Large corporation in the microelectronics industry)

Companies accordingly prefer to enter into collaboration with organizations and individuals with whom they already have a shared working history, and hence consider reliable. Local proximity is of key importance here, as regional networks play two vital roles. First, these networks constitute companies' primary source of contacts and recommendations. Second, they are used as a means of indirect control, as word of satisfaction or dissatisfaction tends to spread throughout the network. The photonics and microelectronics industries both have a highly developed infrastructure of formal and informal platforms on which research organizations and companies interact. Fairs, congresses, business meetings, conferences, and networking events all provide spaces for regular exchange - on both professional and formal, and personal and informal bases.

"The most important thing [in identifying potential partners] is of course always the network you bring along or the network you create through events, conferences, and congresses." (Large corporation in the microelectronics industry)

In addition, it is common practice for companies to actively seek out and contact previously unknown potential collaborators. Job exchanges and employment agencies, on the other hand, were rarely described by our respondents as a means of identifying potential partners.

In the end, although companies tend to emphasize expertise as the major criterion for identifying the "right" partner organization, soft factors such as trust often have a deciding influence. In this respect, innovation ecosystems provide a fertile environment for the initiation of collaboration, as they comprise multiple and dynamic forms of interaction between the relevant actors.

\section{Modes of collaboration}

We now come to an examination of the ways in which companies and research organizations collaborate. 


\section{Collaboration Strategies in Innovation Ecosystems: An Empirical Study of the German Microelectronics and Photonics Industries Fabian Schroth and Johann Jakob Häußermann}

These include both established practices and newly emerging forms of collaboration that are still partly undefined. The exact modes of collaboration companies choose are indicative of their respective perspectives on innovation and general collaboration strategies.

In general, companies look for modes of collaboration and business models that allow for an exchange of complementary competencies without direct competition. In both microelectronics and photonics, joint applications for funding (usually by consortia consisting of different companies and research institutions) and contract research are among the most common types of cooperative relationships. There are various lines of funding for the promotion of collaboration with research institutes in both industries - and despite the administrative effort involved in the application processes and the coordination of consortia, as well as the often difficult negotiations about IP resulting from these projects, almost all of the companies surveyed reported implementing publicly funded collaborative projects. Contract research, in turn, is favoured by some companies because of the clear delineation of rights and obligations between client and contractor.

"We only award contracts that specify that it must be 100\% ours afterwards. When we pay for something, then it is ours and then the contract says: everything you have done belongs to us and you are not allowed to talk about it for so long. But we'll pay for that." (Large corporation in the microelectronics industry)

Companies also often recruit new employees from the staff of their partnered research organizations (or vice versa, in exceptional cases). In addition to formalized and regulated practices, companies also engage in many types of less formalized, short-term collaboration with research establishments, such as taking part in committees and associations or assigning student research projects.

Companies furthermore place great value on longterm strategic partnerships with research organizations, in which they can jointly uncover new markets and research fields while building up a solid basis of trust that also makes it possible to collaborate in legal "grey areas".

In summary, companies and research institutions cooperate and collaborate in a variety of ways, ranging from highly formalized practices such as contract research, through long-term partnerships, to more flex- ible and open forms of collaboration. Preferences for different modes of collaboration reveal general tendencies towards varying strategies within innovation ecosystems. While some companies make use of formalized frameworks to obtain specific knowledge, others prefer to engage with different partners in more open settings, so as to harness the innovative potential of ecosystems.

\section{Success factors and barriers to collaboration}

Finally, we identify factors that foster or impede collaboration between companies and research organizations - and by extension, either foster or impede (or even prevent) the establishment of productive innovation ecosystems.

First, companies are drawn to collaborate with research organizations, as they have a different set of goals to their own (this applies especially to universities). This allows for the joint discovery of new markets and research fields without competitive pressure. Second, companies stand to benefit by gaining access to expertise and research infrastructure. Finally, collaboration with research institutions affords companies access to potential new employees.

On the other hand, respondents in our study noted particular disadvantages to collaboration with research institutions. These include difficulties in IP negotiations and agreeing on codes of conduct, high resource expenditure (particularly in joint projects), protracted processes, a lack of understanding of the business sector's application-oriented approach, a lack of pragmatic approaches to the development of solutions, and conflicting goals as the result of differing interests. In addition, some of the respondents mentioned that in cases where the research organization retains the rights to the generated IP, there is the risk that it will be sold to other companies.

To conclude, differences in objectives are key to collaboration in innovation ecosystems. On the other hand, problems associated with IP and intricate negotiations can hamper collaboration and the development of productive innovation ecosystems. In light of this, companies adopt different strategies - so as to address the challenges of collaboration, and in order to capitalize on the advantages of innovation ecosystems. In the next section, we reduce these strategies to two ideal types.

\section{Discussion}

The empirical findings presented above paint a rather diverse picture of why, how, and with whom companies 


\section{Collaboration Strategies in Innovation Ecosystems: An Empirical Study of the German Microelectronics and Photonics Industries Fabian Schroth and Johann Jakob Häußermann}

in German microelectronics and photonics collaborate, as well as what they perceive to be the main advantages of and barriers to successful collaboration. They reveal that companies often lack an overall, coherent, and explicit collaboration strategy. However, this does not mean that companies do not have implicit strategies. We define collaboration strategies as instruments to facilitate the creation, exchange, and transfer of knowledge in dynamic ecosystems with the aim to develop unique competencies and resources in order to foster competitiveness (Asheim \& Coenen, 2005; Etzkowitz \& Leydesdorff, 2000). Based on our findings, we derived five dimensions of such a strategy along which company collaboration differs. These are the general perspective on innovation; the motivation behind collaborations; the time-frame and mode of collaborations; and the expected outcome. For each of the dimensions, we identified characteristics relating to learning as well as characteristics related to knowledge creation so that we are able to come up with two ideal-typical collaboration strategies (Table 1). The first type describes a strategy that aims at learning; the second aims at creating new knowledge (Asheim \& Coenen, 2005).

Type A represents a strategy to learn from an existing stock of knowledge aiming at incremental innovation, whereas type B represents a collaboration strategy to create new knowledge aiming a radical innovation (Asheim \& Coenen, 2005). The basis of both strategies is a different perspective to innovation processes. Type A is characterized by an understanding of the innovation process as specialized and fragmented. Companies collaborate with research organizations to increase their stock of knowledge in very specialized technological areas. The company predefines the problems to be addressed through cooperation and the solutions that are expected. It tends to favour established practices, such as contract research or joint research projects, with a rather narrow time frame and the aim of developing products or services. More often than not, collaboration is seen as a means to reduce or outsource risk, and to get answers to pre-defined questions and problems aiming at incremental innovations.

Type B is characterized by an understanding of innovation processes in terms of ecosystems. It seeks to harness the potential of diverse and new actors in dynamic relationships, embraces more open and flexible structures, and seeks to develop novel applications, more holistic solutions, and new business models in co-creative collaboration and innovation processes. In short, this strategy aims at radical innovations. This entails an

Table 1. Two ideal types of collaboration strategies

Type A Strategy

A collaboration strategy to learn

Dimension

Perspective on innovation

Motivation for cooperative R\&D\&I

Lacking expertise and resources
Type B Strategy

A collaboration strategy to create new knowledge
Non-linear and complex

Linear and in terms of technology readiness
Develop networks, identify new

trends, and create strategic value
Timeframe for cooperative R\&D\&I

Forms of collaboration

Contract research
Long-term
Various more open modes of collaboration (e.g., joint projects and strategic partnerships) 


\section{Collaboration Strategies in Innovation Ecosystems: An Empirical Study of the German Microelectronics and Photonics Industries Fabian Schroth and Johann Jakob Häußermann}

acceptance of uncertainty and the pursuit of entirely new knowledge, partners, and ideas. Last but not least, type B entails seeking new and more flexible modes of collaboration beyond (lengthy) contract research or joint research projects. This may take the form of collaborative endeavours without pre-defined results, or strategic and long-term yet flexible and dynamic partnerships that accommodate uncertainty.

\section{Conclusion}

In this article, we investigated how companies collaborate with research organizations within a dynamic innovation ecosystem. To this end, we focused on microelectronics and photonics in Germany as examples of knowledge- and research-intensive industries in which digitalization plays a significant role. We explored whether and to what extent companies develop different and new strategies for collaborating with research institutions within innovation ecosystems, on the basis of which we identified two ideal types of strategies. Ideal type A is based on interactive learning from external stocks of knowledge, aiming towards obtaining specific knowledge in order to further develop a particular technology or product, thus at incremental innovation. Ideal type B seeks to create new knowledge and thus to harness the new and full potential of innovation ecosystems. Accordingly, type B embraces complexity and uncertainty, entails looking for new and innovative collaborators, and favours open, flexible, and long-term modes of collaboration

Our study contributes to the conceptual debate on innovation ecosystems by providing empirical insights on how companies and research organizations collaborate in new non-linear and interdependent innovation ecosystems, as identified by Adner and Kapoor (2010) as well as to debates about strategies in innovation ecosystems (Pellikka \& Ali-Vehmas, 2016). Focusing on collaboration strategies, we took analytical concepts developed for national and regional innovation systems (Asheim \& Coenen, 2005; Lundvall, 2007) to analyze reflexive learning activities of companies in innovation ecosystems. Collaboration comprises both learning from existing knowledge and the creation of new knowledge to achieve competitiveness (Asheim \& Coenen, 2005). Based on this understanding, we developed a definition of collaboration strategies in innovation ecosystems as instruments to facilitate the creation, exchange, and transfer of knowledge in dynamic ecosystems with the aim to develop unique competencies and resources in order to foster competitiveness. Our study reveals that companies adopt different col- laborative strategies within innovation ecosystems, aiming at radical as well as incremental innovations. Thus, in contrast to Asheim and Coenen (2005), we were able to show that, in high-tech industries, collaboration strategies are based on either learning from existing stock of knowledge or on creating new knowledge. Taking this diversity into account is helpful in further empirically refining the theoretical concept of innovation ecosystems.

On a more practical level, our study carries a number of implications. Our study highlights the importance for companies of developing appropriate strategies for collaboration with research organizations as the importance of collaboration is strongly increasing. This includes the clear definition of a goal for the collaboration, the systematic search and selection of the partner, and the development and design of a suitable collaboration format. One interesting tool here is, for example, the "University Partnership Canvas", which helps business executives to develop a strategic perspective on such collaborations (Frølund et al., 2018). In particular, our study reveals that the development of long-term, strategic partnerships can be of particularly high added value for companies, although the initiation phase to establish such partnerships can be more complex. Finally, three overarching trends have important implications for the development of corporate collaboration strategies:

1. The growing diversity of players requires not only a careful selection of partners, but also one's own strategic positioning in the innovation ecosystem.

2. Non-linear, dynamic value chains also enable new research partnerships. Here, the development of new collaboration formats is key.

3. Innovation ecosystems provide space for interdisciplinary and cross-sectoral collaboration. This requires not only understanding and appropriate communication channels, but also the creation of internal adoption capacities.

Our research suggests that companies develop a variety of collaboration strategies in response to innovation ecosystems. However, while some companies within innovation ecosystems embrace the new potential of cocreative and dynamic interaction, others continue to employ more linear strategies. At least in the case of the German microelectronics and photonics industries, the two types of strategy currently seem to be equally successful. 


\section{Collaboration Strategies in Innovation Ecosystems: An Empirical Study of the German Microelectronics and Photonics Industries Fabian Schroth and Johann Jakob Häußermann}

\section{About the Authors}

Fabian Schroth is Senior Scientist at the Fraunhofer Center for Responsible Research and Innovation at Fraunhofer IAO. His overall research interest is on sociotechnical innovation processes, and he is particularly interested in realizing the potential of multi-stakeholder engagement for the development of technologies and innovation. Therefore, his current projects focus on innovation in rural areas, the integration of civil society in research, development and innovation processes, and knowledge and technology transfer. He holds a doctoral degree in Sociology. In his doctoral dissertation, he developed an approach of responsible governance experiments in the field of climate politics.

Johann Jakob Häußermann works at the Fraunhofer Center for Responsible Research and Innovation at Fraunhofer IAO in Berlin, Germany, and is currently doing his doctorate at the TUM School of Governance at the Technical University Munich. He holds a Master's Degree in Philosophy, with minors in Politics and Economics. He works at the intersection of ethics, innovation, and technology both from a theoretical as well as practice-oriented perspective. In his $\mathrm{PhD}$, he is developing an integrated concept of responsible innovation that combines the ethics of digital technologies such as artificial intelligence with companies' corporate (digital) responsibility.

\section{Acknowledgements}

This article was developed from a paper presented at the ISPIM Innovation Conference in Stockholm, Sweden, June 17-20, 2018. ISPIM (ispim-innovation.com) the International Society for Professional Innovation Management - is a network of researchers, industrialists, consultants, and public bodies who share an interest in innovation management.

\section{References}

Adner, R., \& Kapoor, R. 2010. Value Creation in Innovation Ecosystems: How the Structure of Technological Interdependence Affects Firm Performance in New Technology Generations. Strategic Management Journal, 31(3): 306-333. https://doi.org/10.1002/smj.821

Asheim, B. T., \& Coenen, L. 2005. Knowledge Bases and Regional Innovation Systems: Comparing Nordic Clusters. Research Policy, 34(8): 1173-1190.

https://doi.org/10.1016/j.respol.2005.03.013

Autio, E., \& Thomas, L. D. W. 2014. Innovation Ecosystems: Implications for Innovation Management? In M. Dodgson, D. M. Gann, \& N. Phillips (Eds.), The Oxford Handbook of Innovation Management. Oxford: Oxford University Press.

Carayannis, E. G., \& Campbell, D. F. J. 2009. 'Mode 3' and 'Quadruple Helix': Toward a 21st Century Fractal Innovation Ecosystem. International Journal of Technology Management, 46(3/4): 201-234.

https://doi.org/10.1504/IJTM.2009.023374

Dolata, U. 2016. Forschung und Entwicklung in der Wirtschaft. In D. Simon, A. Knie, S. Hornbostel \& K. Zimmermann (Eds.), Handbuch Wissenschaftspolitik (2nd ed.). Wiesbaden: Springer VS.

Etzkowitz, H., \& Leydesdorff, L. 2000. The Dynamics of Innovation: From National Systems and "Mode 2" to a Triple Helix of University-Industry-Government Relations. Research Policy, 29(2): 109-123.

https://doi.org/10.1016/S0048-7333(99)00055-4

Frølund, L., Murray, F., \& Riedel, M. 2018. Developing Successful Strategic Partnerships With Universities. MIT Sloan Management Review, 59(2): 71-79.

Häußermann, J. J., Heidingsfelder, M. L., Muschner, A., Schroth, F., Sinell, A., \& Zimmermann, K. 2018. Open Transfer: Ergebnisse des BMBF-geförderten Verbundprojektes zu Wissenschaft-WirtschaftKooperationen in den Branchen Mikroelektronik, Optik sowie Mobilität und Verkehr. Fraunhofer Center for Responsible Research and Innovation (CeRRI); Wirtschaftszentrum Berlin für Sozialforschung (WZB).

Jackson, D. 2011. What is an Innovation Ecosystem? Arlington, VA: National Science Foundation.

Lundvall, B.-A. 2007. National Innovation Systems-Analytical Concept and Development Tool. Industry \& Innovation, 14(1): 95-119.

https://doi.org/10.1080/13662710601130863

Lundvall, B.-Å. 2010. National Systems of Innovation: Toward a Theory of Innovation and Interactive Learning. New York: Anthem.

Pellikka, J., \& Ali-Vehmas, T. 2016. Managing Innovation Ecosystems to Create and Capture Value in ICT Industries. Technology Innovation Management Review, 6(10): 17-24. https://doi.org/10.22215/timreview/1024

Siikonen, J., Pellikka, J., \& Littunen, H. 2011. Knowledge Networks in Innovation among Small KIBS Firms. International Journal of Innovation and Regional Development, 3(5): 515-534. https://doi.org/10.1504/IJIRD.2011.042188

Spectaris. 2010. Branchenbericht 2010: Hightech, Innovation und Wachstum - Die optische, medizinische und mechatronische Industrie in Deutschland. Berlin: Spectaris. 


\section{Collaboration Strategies in Innovation Ecosystems: An Empirical Study of the German Microelectronics and Photonics Industries Fabian Schroth and Johann Jakob Häußermann}

Spectaris. 2014. Photonik Branchenreport: Aktuelle Lage. 2014. Berlin: Spectaris.

Valkokari, K. 2015. Business, Innovation, and Knowledge Ecosystems: How They Differ and How to Survive and Thrive within Them. Technology Innovation Management Review, 5(8): 17-24. https://doi.org/10.22215/timreview/919

VDI. 2016. Agenda Photonik 2020: Update 2016. Der Programmausschuss für das BMBF-Förderprogramm Photonik Forschung Deutschland. Düsseldorf: VDI Technologiezentrum $\mathrm{GmbH}$.

Weber, M. 1904. Die "Objektivität" sozialwissenschaftlicher und sozialpolitischer Erkenntnis. Archiv für Sozialwissenschaften und Sozialpolitik, 19(1): 22-87.

ZVEI. 2017. Die deutsche Elektroindustrie - Daten, Zahlen und Fakten. Frankfurt: Zentralverband Elektrotechnik- und Elektronikindustrie e.V.

Citation: Schroth, F., \& Häußermann, J. J. 2018.

Collaboration Strategies in Innovation Ecosystems: An

Empirical Study of the German Microelectronics and

Photonics Industries. Technology Innovation

Management Review, 8(11): 4-12.

http://doi.org/10.22215/timreview/1195

Keywords: innovation ecosystem, collaboration, photonics, microelectronics, innovation ecosystem strategies, knowledge ecosystem, business ecosystem, research, development and innovation 


\title{
A Strategic Management Maturity Model for Innovation
}

Ferhat Demir

\author{
(6 Building a visionary company requires 1 percent ") \\ vision and 99 percent alignment.
}

Jim Collins and Jerry Porras

In Built to Last (1994)

\begin{abstract}
Even though strategic management is highly critical for all types of organizations, only a few maturity models have been proposed in the business literature for the area of strategic management activities. This article updates previous studies and presents a new conceptual model for assessing the maturity of strategic management in any organization. The Strategic Management Maturity Model for Innovation (S3M-i) is composed of six maturity levels with seven dimensions. The main contribution of the S3M-i is to put innovation into the agenda of strategic management. The main objective of this study is to propose a model to align innovation with business strategies. This article suggests that innovation (new breakthrough products/services and business models) is the only way of creating sustainable growth, and strategy studies cannot ignore this aspect. Maturity models should embrace innovation to respond to the dynamic business environment and rapidly changing customer behaviours.
\end{abstract}

\section{Introduction}

Ever since the industrial revolution, strategic management has been discussed extensively in the related literature. However, like everything, the subject of strategic management has been evolving and changing. In the beginning, strategic management focused on productivity: strategy was driven by efficiency and cost concerns. More recently, with the dawning of the information age and the discovery of breakthrough technologies, corporations have increasingly focused on business intelligence. Collecting and analyzing useful data has become one of the most important agenda items. Today, analyzing data is not sufficient to gain a competitive advantage; it must also lead to new products, services, and unique business models. Unfortunately, the strategy literature has fallen behind this rapid, dramatic change. Strategy studies typically lack the notion of innovation.

The aim of this article is to embed innovation into the strategic management agenda and link innovation to strategy. It seeks to fill a gap in practice and in the related literature: there is currently no up-to-date strategic maturity model addressing the innovation-related needs of today's organizations. The available empirical literature of strategy studies on maturity models and frameworks are scarce. Additionally, new develop- ments, emerging issues, and changing customer behaviours that influence the maturity of strategic management have been neglected. Therefore, this article uses existing models (BSCI, 2010; Demir, 2017) as a foundation but offers a new approach that covers emerging needs and trends, especially as they relate to innovation.

The intent here is not to examine strategic management in depth. Rather, the aim is to develop a model that any organization can use to evaluate the maturity of its strategic management along multiple dimensions. The proposed model is designed to assist executives in identify the maturity level of strategic management in any organization - specifically as it relates to innovation.

\section{Background and Methodology}

Today, many maturity models are based on the capability maturity model (CMM) developed by Carnegie Mellon University in the late 1980s. Maturity models cover a wide range of subjects from organizational development to business analysis. A number of maturity models have been introduced to evaluate different aspects of organizations such as corporate performance management (Aho, 2009), business process management (Fisher, 2004; Melenovsky \& Sinur, 2006; Rosemann et al., 2004), project management (PMI, 2013), and innovation management (Nauyalis, 2013). 


\section{A Strategic Management Maturity Model for Innovation}

\section{Ferhat Demir}

In the research literature based on the CMM, many additional maturity models have been proposed to suit specific contexts, however, none have been developed specifically for strategic management activities for innovation. As a step towards addressing this gap, the author previously conducted a quantitative study to assess the maturity level of 74 research and technology-intensive organizations in Turkey (Demir, 2017). Across a range of sectors, including telecommunications, healthcare, finance, electronics, government, and energy, the results showed that the maturity level of the most organizations is rather modest (typically level 3 on a scale of 1 to 5).

Also, the Balanced Scorecard Institute (BSCI, 2010) has developed a framework called the Strategic Management Maturity Model (SMMM), which provides a foundation for determining strategic management maturity. The SMMM is very useful for quick assessments, but it is relatively old and needs modernization. In particular, it ignores the emerging subject of innovation, which is vital for competition in today's changing business environment. It also mostly focuses on process improvement, which is necessary for cost optimization but is no longer a could source of competitive edge. Indeed, many argue that competition is no longer relevant (e.g., Kim \& Mauborgne, 2005; Thiel, 2014). For sustainable and profitable growth, firms should create entirely new segments where they can monopolize and dominate the market for decades. However, to do so, a high-impact innovation is required.

Therefore, this article builds earlier work by the author (Demir, 2017) and the Balanced Scorecard Institute (BSCI, 2010) to provides a new maturity model, the S3M$\mathrm{i}$, that includes innovation and business model design. The S3M-i takes into account the changing dynamics of the innovation age instead of concentrating on productivity, which was the biggest concern and the most important competitive edge of the industrial age. The model proposed in this study aims to fill the gap between strategy and innovation. It is because innovation is the only driver of competition in today's world. This aspect is the key difference between the S3M-i and the SMMM by the Balanced Scorecard Institute (BSCI, 2010). However, the expectations of the two models from a strategic management perspective are also different. The ultimate purpose of strategic management should not be continuous improvement (BSCI, 2010) but continuous innovation. Thus, there is no need to include process improvement as a separate dimension. The goal is not to improve business processes but to dominate the market. Processes should be designed and re-engineered to foster innovation. Organizations that optimize their operations and business processes are productive, but only excellent organizations are innovative.

The new model is designed to be more comprehensive and more structured than previous models. The steps of strategic management and levels of the maturity remain same; however, the dimensions of the model are updated. Seven dimensions are presented instead of five and five of the dimensions are newly proposed. Also, given that the characteristics and capabilities of organizations vary by their strategic management maturity level, new organizational types at different stages are suggested. Additionally, and more importantly, a maturity assessment chart is presented in this study. It is highly critical to determine the accurate level of maturity.

Up to this point, the development of the model has been largely qualitative (with the notable exception of the author's quantitative assessment of 74 organizations in Turkey: Demir, 2017). Other maturity models have been examined in depth and broader analyses of interdisciplinary studies have been undertaken. The work has also been informed by careful examination of the relevant scholarly and practical literature (e.g., Baird et al., 2007; Nedelfa \& Paun, 2009; Ries, 2011; Thiel, 2014; Valencia et al., 2010; Yarbrough et al., 2011).

\section{Introducing the Strategic Management Maturity Model for Continuous Innovation}

\section{The need for a strategic management process}

Strategic management is traditionally a three-step process that includes planning, execution, and monitoring. However, in today's business environment, it has to go beyond just these three steps and be more comprehensive. Organizations face multiple challenges in this era. External factors such as advanced technologies, emerging demographic groups, and totally new customer behaviours shape everything dramatically and faster than ever before.

Innovation is the only way to stay up-to-date and strategic management cannot ignore it. If you cannot change the game, then you need to be satisfied with a modest growth and should feel lucky because your business has not died. Only firms that create a radical shift from existing markets and totally new business can achieve strong profitable growth.

Kim and Mauborgne (2005) argue that extraordinary companies will succeed not by competing, but by systematically creating blue oceans of niche market-space 


\section{A Strategic Management Maturity Model for Innovation}

\section{Ferhat Demir}

ripe for rapid growth. The key to exceptional business success is to redefine the terms of competition and move into the "blue ocean".

When a company slightly improves its processes and competes with existing products in the market, little value within the business is created. Thiel (2014) argues that enormous value can be created when a business creates something new and fresh.

Strategic planning is no longer only a business improvement tool; it should also be an innovation accelerator. In today's competitive arena, companies need a more dynamic strategy, and that is possible only when innovation and strategy are linked. Strategic management must not end with the last annual meeting. The only valuable output of a strategic management process is a radically new product/service with a totally new industry and market.

It is usually considered that strategic management has five critical components: defining the business, establishing objectives, formulating the strategy, strategy implementation and execution, and evaluating performance (Nedelfa \& Paun, 2009). New developments, emerging trends, changing behaviours, new rules of competition, and the complex patterns of today's business environment should be added to classic management systems - especially the strategic management process. New elements, such as innovation, should be added to the main stages of strategic management referred to above.

Thus, this article proposes that a strategic management process should include five mandatory steps - leadership, formulation, execution, integration, and innovation - as illustrated in Figure 1. Thus, this article claims that strategic management starts with a visionary leadership, but only excellent organizations, in terms of strategic management, are innovative. Sustainable innovation requires effective planning, implementation, and measurement of results. Organizations that learn from this process constantly and align their components according to their strategy can achieve continuous innovation.

Any strategy development process must count on visible commitment from the executive team. Leaders provide the vision, set the long-term goals, and create unique values that distinguish the business and create sustainable growth. Strategic leadership starts with a comprehensive and holistic analysis, the focus of which should be on creating a strategic direction and identify- ing initiatives that will help the business grow. All external or internal issues that can affect goals and objectives must be examined. Leaders who have a vision but are charismatic and have strong managerial skills can provide the glue to bring people together and foster effective teamwork for common goals. The task of formulating the strategy entails taking into account all of the relevant aspects of the organization's internal and external conditions and coming up with a detailed action plan for achieving the targeted results (Nedelfa \& Paun, 2009).

To develop the action plan, priorities must be established by considering the weaknesses, needs, strengths, and competencies of the organization. In the formulation phase, goals and objectives should be determined and strategies need to be developed. Also, a comprehensive and dynamic strategic plan should be prepared to address all goals, strategies, critical success factors, and actions. A customized process for each employee should be identified so each person knows their specific task to accomplish long-term goals within a determined budget.

Successful implementation is critical to the success of the business venture. In the execution stage, organizations should be governed by their strategic plan so they can achieve the strategic goals. Strategic plans should

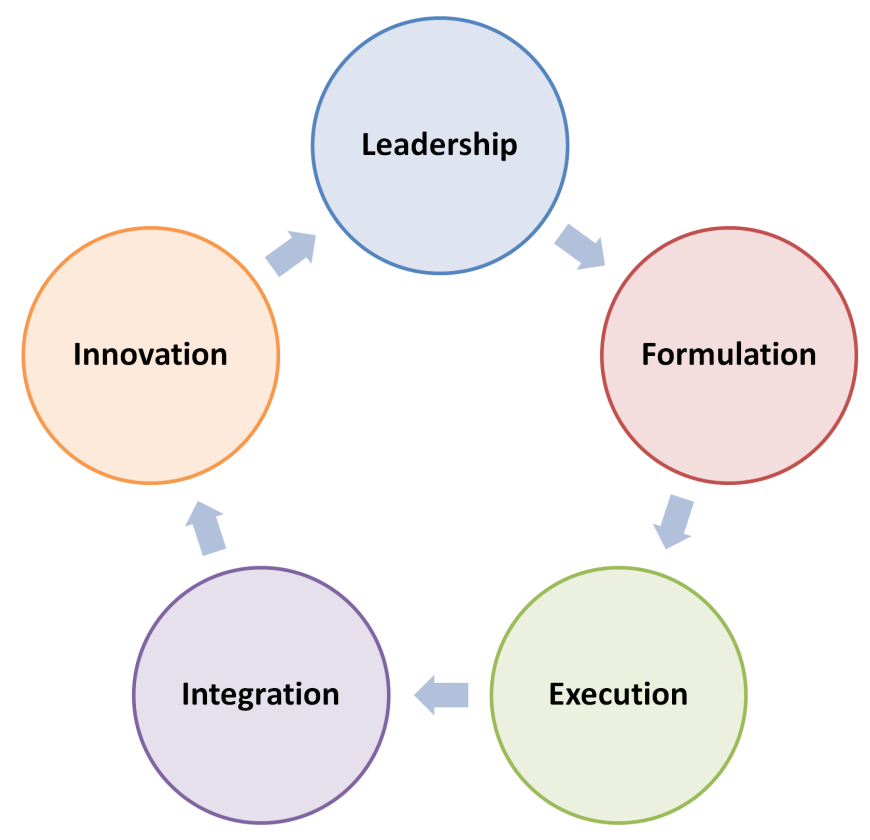

Figure 1. The five proposed steps for a strategic management process 


\section{A Strategic Management Maturity Model for Innovation}

\section{Ferhat Demir}

be regularly revised. Everyone within the organization must have a clear understanding of their responsibilities and how that fits in with the overall strategic goals. At this stage, organizations should communicate their plan, manage the implementation of the plan, supervise the actual work, and monitor the progress.

Organizations that are continuously learning and evolving should be constantly redesigned and managed based on performance results. They apply strategies, measure results, and improve their capability continuously through a feedback loop. Also, business processes and operations are optimized in response to performance indicators. More importantly, if the overall strategy does not work with the business' current structure, business model, and culture, a new structure should be installed, a new business model should be generated, and a new culture should be formed. In the integration stage, each component of the organization such as structure, culture, business model, processes, and systems should be aligned with the strategy (BSCI, 2010). Also, management must remember that people and other resources are not only driven by strategy, they also must apply strategies, measure results, and improve their capability continuously.

This study claims that only fully integrated and effectively managed organizations can achieve sustainable innovation. One-time breakthrough innovation may be possible; however, a plan, execution, and 360-degree integration are needed for continuous innovation. Ries (2011) argues that entrepreneurship is management and a new kind of management along with structured methodologies are necessary for innovation. Thus, innovation can be possible and predictable instead of being a lottery - but only if analysis, planning, and implementation are done effectively.

\section{The seven dimensions of strategic management}

The strategic management maturity model for innovation (S3M-i) introduced in this article is composed of seven different dimensions of strategic management:

1. Leadership

2. Planning \& Executing

3. Processes \& Tools

4. Structure \& Model

5. People \& Culture

6. Performance Management

7. Innovation
Basically, the model covers the entire process of strategic planning from visionary leadership to execution. Also, it touches each area of strategic management including strategy formulation and aligning organizational components with business strategies.

Some dimensions may require more effort along with a skilled workforce. For instance, innovative organizations require various sophisticated techniques, highly qualified teams, and advanced systems. Therefore, it might be more challenging to reach the highest level of maturity (Level 5).

Below are descriptions of the proposed seven dimensions of the strategic management process:

1. Leadership: A key aspect of strategic management is the development of a viable structure of leadership and decision making (BSCI, 2010). A full commitment of executive teams should be seen in any strategy formulation and development process (Demir, 2017). Obviously, strategic management cannot succeed without powerful leadership and full support of top management. Leaders set a common vision and make employees believe in it. Leaders work with their teams toward common goals. Strategic leaders encourage innovation at all levels and transform the business and organizational culture to become more innovative

2. Planning \& Executing: No sustainable success is possible without an effective plan. Without implementation, the strategy is merely a hallucination. A strategic plan - including goals/objectives and actions - must be prepared. Strategies should be implemented and then progress should be monitored. Excellent organizations are governed by their strategic plan, and innovation is an important part of the strategic plan. Also, strategy drives all critical decisions in such organizations.

3. Processes \& Tools: Strategic management processes should be documented, regularly analyzed, and improved to start building an excellent enterprise. More importantly, processes are designed for continuous innovation in such an enterprise. The focus is not process improvement but market disruption. Therefore, processes are flexible, agile, and lean. The innovation strategy drives the re-engineering of business processes. Advanced tools and techniques are used to foster innovation. Also, all processes, operational systems, and technologies are integrated into corporate strategies. 


\section{A Strategic Management Maturity Model for Innovation}

\section{Ferhat Demir}

4. Structure \& Model: This dimension refers to the organizational structure and business model. Both should support strategies. Excellent organizations align their structure and business model with corporate strategies. In other words, the organizational structure and business model are designed to achieve long-term strategic goals. Additionally, the model and the structure are tools to foster innovation. Through low hierarchy and a flat and agile organization, a dynamic, competitive, and highly innovative business model can be shaped.

5. People \& Culture: Baird, Harrison, and Reeve (2007) have argued that culture and strategy should be aligned for the success of the organization. Futhermore, Valencia, Valle, and Jiménez (2010) claimed that innovation strategies are produced by adhocracy culture. Finally, Yarbrough, Morgan, and Vorhies (2011) have proposed that the link between organizational culture and strategy affects the results and performance of an organization. Thus, in excellent organizations, culture is fully aligned with strategies. They are less bureaucratic, innovation is a core value, and their culture cultivates innovation. Employees in such organizations are always encouraged to come up with new ideas.

6. Performance Management: You cannot manage what you do not measure. Excellent organizations have a set of performance indicators and metrics. They routinely measure the performance of critical areas. Innovation is a key success factor. They assign key performance indicators (KPIs) for innovation activities. The most important performance indicator is the outcome of disruptive innovation such as totally new product/service, market, or business model.

7. Innovation: As important as it is to clearly design the firm's technological strategy, it is to promote its alignment with business strategy, integrating all departments and regarding the firm's current capabilities. Although necessary for achieving profitable solutions, strategic alignment is a commonly neglected step of the innovation process (Zawislak \& Marins, 2007).

Only fully integrated organizations can achieve sustainable innovation. In excellent organizations, innovation initiatives are well aligned with corporate strategies. When a significant level of maturity and degree of integration have been reached, the firm is on a journey of continuous innovation. Disruptive, game-changing innovations can only be developed by organizations that have a high level of strategic management maturity.
Such enterprises embed innovation in organizational culture and radical innovation is a part of their organizational DNA.

\section{Levels of strategic management maturity for innovation} For each of the seven dimensions described above, there are six levels of strategic management maturity for innovation (Figure 2). Organizations can be assessed by evaluating the degree of performance on each of the six levels of maturity.

- Level 0: Undefined: Nothing is defined at this level. Things are turbulent and organizations may go through a chaotic storming stage. There is no structured strategic management process, and no one has been designated as responsible for strategic management activities. However, a strong entrepreneurial spirit is present.

- Level 1: Initial: At this level, an owner is assigned to strategic planning. However, the organization still does not plan things in a formal way. Some tactical plans might take a place, but leaders spend the majority of their time dealing with operational issues. Some components of the business model may be known, but no model has been fully designed. Innovation is the result of the efforts of the founders.

- Level 2: Planned: At this level, organizations apply a strategic plan only partially and with poor results. Business strategies are formulated. Goals and objectives are set. However, strategic management activities are undertaken by certain individuals. Rather than strategic goals, organization-wide standards

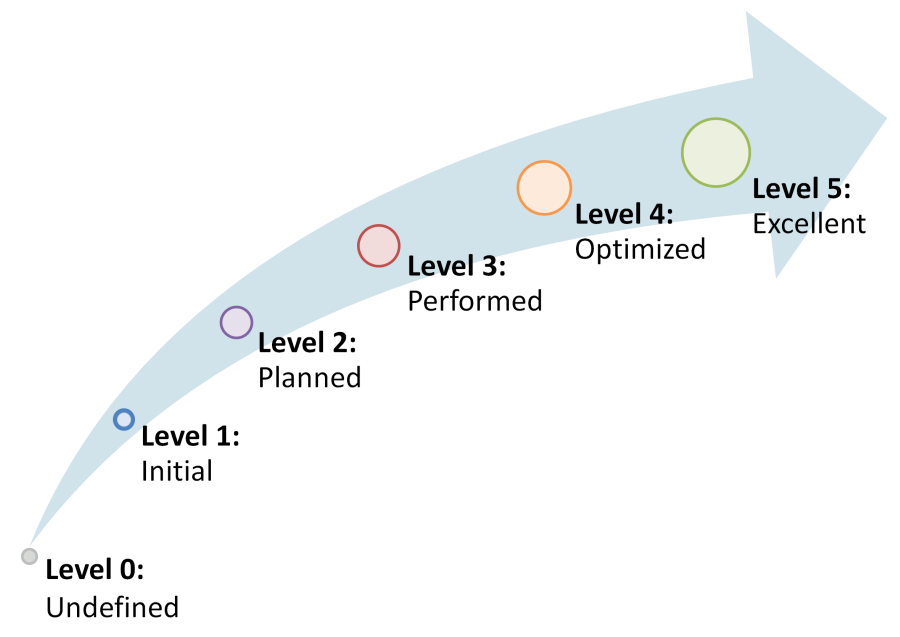

Figure 2. The six levels of strategic management maturity for innovation 


\section{A Strategic Management Maturity Model for Innovation}

\section{Ferhat Demir}

provide guidance across business units. An innovation management process might be defined but no structured method is used.

- Level 3: Performed: At this level, a structured and comprehensive plan is in place, and formal processes and procedures are followed. People cross business units to engage in strategic management activities. Performance reviews are done regularly. Top management involves and monitors closely the pursuit of strategies. Vision, goals, and values are communicated effectively but lack of linkage between organizational culture and strategy. Organizational structure and business model may not fit strategies. Bureaucratic culture and tall organizations are common. Innovation is not a critical item on the agenda. Some incremental innovations may occur, mostly by chance or as a consequence of random activities.

- Level 4: Optimized: At this level, leaders and employees fully engage with strategic management processes. Strategic initiatives are updated regularly. Performance results are measured. Items in the strategic plan are revised according to performance reviews. The strategic direction of the organization is shifted based on performance results. The organization structure and business model support long-term goals and strategies. Organizational culture is transforming from bureaucracy to adhocracy. The organization's stability provides a ground for innovation. People fully engage with innovation activities but there still a gap between strategy and innovation.

- Level 5: Excellent: At this level, innovation is embedded within the culture of the organization. The innovation focus is sustainable breakthrough products/services and business models. At this level, all components of the organization are integrated very well. Innovation strategies are formulated and aligned with business strategies. The organization is finely tuned for strategic innovation.

\section{Organizational focus across maturity levels}

The characteristics of organizations vary from one maturity level to another. Each level has its own organizational focus and concern. Table 1 indicates how organizational focus/type varies by maturity level. This article calls innovative those organizations that are highly capable of having strategic management with an excellent level of maturity. Only firms who are excellent in strategic management can accomplish sustainable innovation. At the beginning of their organizational lifecycle, most startups do not have a clear strategy or structured processes to execute their strategy. They might have a brilliant idea and see a big opportunity in a niche market. However, to pursue the idea and shift the organization to the next level, an organization needs more than just an entrepreneurial spirit. Planning, clear goals, defined processes, structured models, effective team management, execution, learning, and revising/redesigning consequently are necessary for high-impact innovations. But, before becoming highly innovative, organizations must first become highly effective and productive. A continuous strategic management cycle will eventually take organizations who learn from their mistakes to the top of the innovation league.

\section{Assessing strategic management maturity for innovation} using the S3M- $i$

An organization's overall maturity level is important, but it is also helpful to recognize strengths and identify areas for improvement. After all, it is rare to find an organization that is uniformly mature across all dimensions. For instance, an organization might be at Level 4 for Leadership but at Level 2 for Processes \& Tools. The matrix in Table 2 provides guidance for assessing the maturity level of an organization along each of the seven dimensions. The overall maturity level of the organization is the mean score across the seven dimensions, rounded to the nearest whole number. As an example, if the mean score across the seven dimensions is 2.7, the overall maturity level of that organization is Level 3.

Table 1. Organizational type/focus at each level of strategic management maturity for innovation

\begin{tabular}{ll} 
Maturity Level & Organizational Type/Focus \\
\hline Level 0: Undefined & Inexplicit \\
\hline Level 1: Initial & Entrepreneurial \\
\hline Level 2: Planned & Specified \\
\hline Level 3: Performed & Effective \\
\hline Level 4: Optimized & Productive \\
\hline Level 5: Excellent & Innovative
\end{tabular}




\section{A Strategic Management Maturity Model for Innovation}

\section{Ferhat Demir}

Table 2. A matrix for assessing strategic management maturity for innovation

\begin{tabular}{|c|c|c|c|c|c|c|}
\hline & $\begin{array}{l}\text { Level 0: } \\
\text { Undefined }\end{array}$ & $\begin{array}{l}\text { Level 1: } \\
\text { Initial }\end{array}$ & $\begin{array}{l}\text { Level 2: } \\
\text { Planned }\end{array}$ & $\begin{array}{l}\text { Level 3: } \\
\text { Performed }\end{array}$ & $\begin{array}{l}\text { Level 4: } \\
\text { Optimized }\end{array}$ & $\begin{array}{l}\text { Level 5: } \\
\text { Excellent }\end{array}$ \\
\hline Leadership & $\begin{array}{l}\text { No organizational } \\
\text { awareness of } \\
\text { strategic } \\
\text { leadership }\end{array}$ & $\begin{array}{l}\text { Knowledge exists, } \\
\text { but no owner and } \\
\text { sponsor for } \\
\text { strategic } \\
\text { management } \\
\text { activities }\end{array}$ & $\begin{array}{l}\text { An employee is } \\
\text { assigned to strategic } \\
\text { projects and activities }\end{array}$ & $\begin{array}{l}\text { A team performs } \\
\text { strategic activities; the } \\
\text { team leader engages } \\
\text { with other } \\
\text { department managers }\end{array}$ & $\begin{array}{l}\text { A particular office } \\
\text { leads strategic } \\
\text { management } \\
\text { activities effectively; } \\
\text { leaders and } \\
\text { employees fully } \\
\text { engagein strategic } \\
\text { management } \\
\text { processes }\end{array}$ & $\begin{array}{l}\text { Strategicleadership } \\
\text { encourages } \\
\text { innovation at all } \\
\text { levels; leaders } \\
\text { transform the } \\
\text { business and culture } \\
\text { to become more } \\
\text { innovative }\end{array}$ \\
\hline $\begin{array}{l}\text { Planning \& } \\
\text { Executing }\end{array}$ & $\begin{array}{l}\text { No organizational } \\
\text { awareness of } \\
\text { strategic planning }\end{array}$ & $\begin{array}{l}\text { No strategic plan; } \\
\text { some goals and } \\
\text { objectives are } \\
\text { defined }\end{array}$ & $\begin{array}{l}\text { Strategic planning is } \\
\text { the responsibility of } \\
\text { one person and a } \\
\text { strategic plan is } \\
\text { prepared every } 4-5 \\
\text { years }\end{array}$ & $\begin{array}{l}\text { A structured and } \\
\text { interactive strategic } \\
\text { planning process } \\
\text { exists; actions plans } \\
\text { are developed }\end{array}$ & $\begin{array}{l}\text { Strategic plan/actions } \\
\text { plans are revised } \\
\text { regularly; strategic } \\
\text { initiatives are updated }\end{array}$ & $\begin{array}{l}\text { Strategy drives all } \\
\text { critical } \\
\text { organizational } \\
\text { decisions; innovation } \\
\text { is an important } \\
\text { agenda of the } \\
\text { strategic plan }\end{array}$ \\
\hline $\begin{array}{l}\text { Processes \& } \\
\text { Tools }\end{array}$ & $\begin{array}{l}\text { No process and } \\
\text { tools for strategic } \\
\text { management } \\
\text { activities }\end{array}$ & $\begin{array}{l}\text { Some ad-hoc } \\
\text { reports and tools } \\
\text { are used, but } \\
\text { processes are } \\
\text { undocumented }\end{array}$ & $\begin{array}{l}\text { A few key processes } \\
\text { are documented; } \\
\text { some basic tools are } \\
\text { used for strategic } \\
\text { planning and } \\
\text { management }\end{array}$ & $\begin{array}{l}\text { All strategic } \\
\text { management } \\
\text { processes are mapped } \\
\text { out and analyzed, and } \\
\text { strategy drives } \\
\text { process } \\
\text { improvements }\end{array}$ & $\begin{array}{l}\text { All strategic processes } \\
\text { are redesigned for } \\
\text { continuous } \\
\text { innovation; advanced } \\
\text { tools/methods are } \\
\text { used for strategic } \\
\text { planning and } \\
\text { innovation } \\
\text { management }\end{array}$ & $\begin{array}{l}\text { There is a structured } \\
\text { innovation } \\
\text { management process; } \\
\text { strategy guides } \\
\text { selection of tools and } \\
\text { technologies; all } \\
\text { tools/systems are } \\
\text { integrated into } \\
\text { strategies }\end{array}$ \\
\hline $\begin{array}{l}\text { Structure \& } \\
\text { Model }\end{array}$ & $\begin{array}{l}\text { Organizational } \\
\text { structure and } \\
\text { business model } \\
\text { are unknown }\end{array}$ & $\begin{array}{l}\text { Chaotic } \\
\text { organizational } \\
\text { structure; some } \\
\text { components of } \\
\text { business model } \\
\text { are known }\end{array}$ & $\begin{array}{l}\text { Functional } \\
\text { organizational } \\
\text { structure is created; } \\
\text { business model is } \\
\text { defined }\end{array}$ & $\begin{array}{l}\text { Rigid structure } \\
\text { (hierarchy is } \\
\text { important; tall } \\
\text { organization); } \\
\text { business model is not } \\
\text { innovative; structure } \\
\text { and model do not } \\
\text { support strategies }\end{array}$ & $\begin{array}{l}\text { Organizational } \\
\text { structure and } \\
\text { business model are } \\
\text { redesigned to foster } \\
\text { innovation and } \\
\text { empower strategies; } \\
\text { flat organization with } \\
\text { low hierarchy }\end{array}$ & $\begin{array}{l}\text { Organizational } \\
\text { structure and } \\
\text { business model are } \\
\text { fully integrated into } \\
\text { strategies; a } \\
\text { unique/innovative } \\
\text { business model; an } \\
\text { agile structure }\end{array}$ \\
\hline $\begin{array}{l}\text { People \& } \\
\text { Culture }\end{array}$ & $\begin{array}{l}\text { No common } \\
\text { values and } \\
\text { personas }\end{array}$ & $\begin{array}{l}\text { Values are } \\
\text { undefined; an } \\
\text { organizational } \\
\text { culture is not } \\
\text { formed yet }\end{array}$ & $\begin{array}{l}\text { People share a } \\
\text { common vision and } \\
\text { values are } \\
\text { understood; } \\
\text { innovation is a critical } \\
\text { value }\end{array}$ & $\begin{array}{l}\text { Vision, goals, and } \\
\text { values are } \\
\text { communicated; } \\
\text { organizational culture } \\
\text { is fully formed but } \\
\text { culture is not linked to } \\
\text { strategy; bureaucratic } \\
\text { culture }\end{array}$ & $\begin{array}{l}\text { Organizational } \\
\text { culture is redesigned } \\
\text { to support innovation } \\
\text { strategies; less } \\
\text { bureaucracy, a more } \\
\text { adhocratic culture is } \\
\text { forming }\end{array}$ & $\begin{array}{l}\text { Organizational } \\
\text { culture fully } \\
\text { integrated into } \\
\text { strategies; culture is } \\
\text { innovation focused; } \\
\text { people are } \\
\text { encouraged to come } \\
\text { up with new ideas }\end{array}$ \\
\hline $\begin{array}{l}\text { Performance } \\
\text { Management }\end{array}$ & $\begin{array}{l}\text { No assigned } \\
\text { performance } \\
\text { indicators }\end{array}$ & $\begin{array}{l}\text { Few performance } \\
\text { indicators are } \\
\text { identified but no } \\
\text { available data }\end{array}$ & $\begin{array}{l}\text { All performance } \\
\text { indicators and metrics } \\
\text { are identified; no KPI } \\
\text { for innovation }\end{array}$ & $\begin{array}{l}\text { Strategicindicators } \\
\text { are measured data } \\
\text { collected, and overall } \\
\text { performance is } \\
\text { managed at a broad } \\
\text { level; KPIs are } \\
\text { designed for } \\
\text { innovation activities }\end{array}$ & $\begin{array}{l}\text { Strategicindicators } \\
\text { are revised according } \\
\text { to performance } \\
\text { results; innovation } \\
\text { performance is } \\
\text { managed at all levels }\end{array}$ & $\begin{array}{l}\text { Systems are } \\
\text { implemented for } \\
\text { disruptive innovation; } \\
\text { performance of } \\
\text { radical innovation is } \\
\text { measured daily basis }\end{array}$ \\
\hline Innovation & $\begin{array}{l}\text { Innovation is not } \\
\text { a priority }\end{array}$ & $\begin{array}{l}\text { Random } \\
\text { innovations, not } \\
\text { results of a } \\
\text { structured } \\
\text { approach }\end{array}$ & $\begin{array}{l}\text { Innovation } \\
\text { management process } \\
\text { is defined but no tool } \\
\text { and method are used } \\
\text { for innovation }\end{array}$ & $\begin{array}{l}\text { Innovation initiatives } \\
\text { are started; structured } \\
\text { innovation } \\
\text { tools/techniques/met } \\
\text { hods are used at some } \\
\text { organizational levels; } \\
\text { mostly incremental } \\
\text { innovation takes } \\
\text { place }\end{array}$ & $\begin{array}{l}\text { People fully engage in } \\
\text { innovation activities } \\
\text { at all levels; some } \\
\text { radical innovations; } \\
\text { semi-innovative } \\
\text { organization; gap } \\
\text { between strategy and } \\
\text { innovation }\end{array}$ & $\begin{array}{l}\text { Innovation initiatives } \\
\text { are well aligned with } \\
\text { corporate strategies; } \\
\text { fully innovative } \\
\text { organization; } \\
\text { disruptive innovation } \\
\text { is part of DNA }\end{array}$ \\
\hline
\end{tabular}




\section{A Strategic Management Maturity Model for Innovation}

\section{Ferhat Demir}

\section{Conclusions}

To assess the maturity level of strategic management practices, this article has attempted to propose a new model by revising previous studies (BSCI, 2010; Demir, 2017). Although the S3M-i is still in a testing stage, it can help understand, analyze, and improve strategic management activities in any type of organization.

This article provides several novel contributions to the literature. First, it updates existing models and introduces a new model for identifying strategic management maturity. Even though the research literature includes maturity models for business process management, project management, and organizational maturity, no model addressed strategic management specifically. Second, this article presents a new strategic management cycle, which is more up-to-date. Third, the article also shows the type and focus of organizations at different maturity levels. Last, and maybe most important, this article highlights the importance of the link between strategy and innovation. It proposes aligning innovation with business strategies as a part of strategic management. Integration of all organizational components, especially innovation studies with corporate strategies, is critical for sustainable growth.

The S3M-i model introduced in this article aims at continuous innovation. Only those organizations that align innovation with a strategy and constantly improve strategic management activities should be considered as "excellent". To reach an excellent level of maturity, organizations should not only prepare and implement a strategic plan but also optimize strategic management processes and align all organizational components including innovation (Demir, 2017).

This study is a further step to measure maturity levels of strategic management. However, the model introduced in this article should be tested in future studies. A number of companies with a good sample size should be assessed using results from in-depth interviews with a comprehensive question set covering all seven dimensions. Examinations with different sizes of organizations in different industries and regions are worth further consideration and analyses. Further studies are necessary to probe deeper into the measurement of strategic management practices that are highly critical for creating innovative organizations and developed economies. Overall, the study has provided valuable material for both practitioners and academics.
The S3M-i model is still in a testing phase, but it can be used for any type of organization in any industry. One of the biggest contributions of the new model is obviously the essence of innovation. It provides a foundation to integrate innovation efforts with strategic management activities throughout an organization.

\section{About the Author}

Ferhat Demir is a management lecturer, trainer, and consultant. He studied Industrial Engineering at the Sakarya University in Adapazarı, Turkey. He received his Master of Business Administration (MBA) degree from Kennesaw State University and his Master of Public Policy (MPP) degree from Georgia State University in the United States. His fields of expertise and research interests include strategic management, innovation strategies, competitiveness, business models, and organizational design. He has diverse experience with large corporations, SMEs, non-profit organizations, and governmental institutions.

\section{References}

Aho, M. 2009. A Capability Maturity Model for Corporate Performance Management - An Empirical Study in Large Finnish Manufacturing Companies. In Proceedings from the eBRF, A Research Forum to Understand Business in Knowledge Society: 1-20. September 2009, Jyväskylä, Finland.

Baird, K., Harrison G., \& Reeve, R. 2007. The Success of Activity Management Practices: The Influence of Organizational and Cultural Factors. Accounting \& Finance, 47(1): 47-67. https://doi.org/10.1111/j.1467-629X.2006.00195.X

BSCI. 2010. The Strategic Management Maturity Model. Cary, NC: Balanced Scorecard Institute (BSCI). http://www.balancedscorecard.org/Portals/0/PDF/BSCIStrategicM anagementMaturityModel.pdf

Demir, F. 2017. Measuring Strategic Management Maturity: An Empirical Study in Turkish Public and Private Sector Organizations. World Academy of Science, Engineering and Technology International Journal of Economics and Management Engineering, 11(11): 2433-2440. https://doi.org/10.5281/zenodo.1132681

Fisher, D. M. 2004. The Business Process Maturity Model: A Practical Approach for Identifying Opportunities for Optimization. BPTrends, September 7, 2004. Accessed July 24, 2017:

https://www.bptrends.com/the-business-process-maturity-modela-practical-approach-for-identifying-opportunities-foroptimization/ 


\section{A Strategic Management Maturity Model for Innovation \\ Ferhat Demir}

Kim, W. C., \& Mauborgne, R. 2005. Blue Ocean Strategy. Boston, MA: Harvard Business School Publishing Corporation.

Melenovsky, M. J., \& Sinur, J. 2006. BPM Maturity Identifies Six Phases for Successful BPM Adoption. Gartner, October 18, 2006. Accessed July 24, 2017:

https://www.gartner.com/doc/497289/bpm-maturity-modelidentifies-phases

Nedelfa, S., \& Paun, L. A. 2009. The Importance of the Strategic Management Process in the Knowledge-Based Economy. Review of International Comparative Management, 10(1): 95-105.

PMI. 2013. Organizational Project Management Maturity Model: OPM3 Knowledge Foundation (3rd Ed.). Newtown Square, PA: Project Management Institute (PMI).

Nauyalis, C. 2013. A New Framework For Assessing Your Innovation Program: Introducing The Innovation Management Maturity Model. Austin, TX: Planview.

http://www2.planview.com/im3/docs/Planview-InnovationMaturity-Model.pdf

Ries, E. 2011. The Lean Startup. New York: Crown Publishing Group.

Rosemann, M., de Bruin, T., \& Hueffner, T. 2004. A Model for Business Process Management Maturity. In Proceedings of the 2004 Australasian Conference on Information Systems (ACIS), Paper 6. December 1-3, 2004, Hobart, Australia.

Thiel, P. 2014. Zero to One. New York: Crown Publishing Group.

Valencia, J. C. N., Valle, R. S., Jiménez, D. 2010 . Organizational Culture as Determinant of Product Innovation. European Journal of Innovation, 13(4): 466-480.

https://doi.org/10.1108/14601061011086294

Yarbrough, L., Morgan, N. A., \& Vorhies, D. W. 2011. The Impact of Product Market Strategy-Organizational Culture Fit on Business. Journal of Academy of Marketing Science, 39(4): 555-573. http://doi.org/10.1007/s11747-010-0238-x

Zawislak, P. A., \& Marins, L. M. 2007. Strengthening Innovation in Developing Countries. Journal of Technology Management and Innovation, 2(4): 44-54.

Citation: Demir, F. 2018. A Strategic Management Maturity Model for Innovation. Technology Innovation

Keywords: strategic management, innovation, business model, maturity model 


\title{
A Practice Method for Studying Creative Communities
}

\author{
Pekka Buttler
}

\author{
'Innovation, like creativity, is an amorphous \\ concept. It's the holy grail of business, but \\ achieving it - even merely explaining it - is \\ lightning-in-a-bottle difficult.
}

Adam Lashinsky (2017)

Executive Editor, Fortune

\begin{abstract}
Explaining innovation - even merely spotting it actually happening - is difficult. In this article, I introduce an industry-friendly approach that will enable practitioners and researchers alike to observe, interpret, and understand the different types of creativities - the raw materials necessary for innovation - that happen in creative communities. The Practice Method for Studying Creative Communities (PMSCC) is based on theories developed by Nonaka and Takeuchi. However, unlike mainstream practice-oriented methods, the PMSCC does not necessitate the use of theory-heavy conceptualizations; instead, it focuses on the everyday, creative micro-interactions in communities. As I describe in this article, the PMSCC offers practitioners and researchers an effective way to gain new insights into an otherwise relatively opaque process. Besides outlining the method, I also present results from a research project utilizing the PMSCC, showing how the method can produce worthwhile findings, foster new insights, and help practitioners hone their creative processes.
\end{abstract}

\section{Introduction}

In cartoons, flashes of brilliance are easy to spot - the character strikes a contemplative pose, or is jolted into an energetic position, while a bulb lights up above the character's head. In real life, there are no lightbulbs, and while contemplating or thinking hard might sometimes be conducive to creativity, there might not be a big idea or moment of innovation - merely a long, gradual progression. What makes real-life creativity and innovation even more difficult to spot, is that it mostly does not happen within people, but between people, in social interactions (Nonaka et al., 2008). Nevertheless, many still think of innovation and study innovation as if it does happen just like in cartoons. However, we cannot afford to oversimplify the creative process - increasingly, positive outcomes depend on a keen understanding of the origins of innovation.

Indeed, innovation holds the key for solving most major problems facing companies (see Cohendet \& Simon, 2015), the future generations (e.g., European Commission, 2013), national economies (e.g., UK Government
Office for Science, 2017; Prime Minister's Office of Finland, 2015), even humanity as a whole (e.g., Intergovernmental Panel on Climate Change, 2005). Thus, one would assume that we would be well-equipped to study innovation, or - if not - that we would be focusing on developing that capability.

But we are not. Even though science has long recognized the importance of innovation, most research is not geared towards helping us learn how to achieve or understand it. As Anderson, de Dreu, and Nijstad (2004) found, innovation studies published in top journals are dominated by approaches based on replication or extension, and only a small minority are driven by theory or derived from real-world problems. Moreover, they found that, in studying innovation, creativity has not received much attention.

West (2002) argues that innovation is, "a two-component, but essentially non-linear process, encompassing both creativity and innovation implementation". Creativity and innovation are thus associated but distinct (Runco, 2014): creativity is "raw material" for innovation 


\section{A Practice Method for Studying Creative Communities}

\section{Pekka Buttler}

(Valgeirsdottir \& Onarheim, 2017); innovation begins with creativity (Serrat, 2017); and creativity is "thinking", whereas implementation is "doing" (West, 2002), with the most promising ideas being selected for implementation (Forde \& Fox, 2016). Significantly, Cummings, Bilton, and ogilvie (2015) argue for conceptualizing creativity not as normative, singular, and static, but as pluralistic ("creativities") and as dynamic ("creativitying").

Although implementation is what makes creativities both significant and visible, without creativities, there is little to implement. Aphoristically, innovation is a forest of invisible trees: we see the results of innovations around us, but creativities often stay hidden; we lionize the successful innovator, but do not see the community supporting and enabling our genius idol. Hence, to understand the origins of innovation, we need the ability to observe and understand the activities of creative communities and the ideation process (Cohendet \& Simon, 2015), implying that we need to focus on creativity - not as an abstract concept, but on a very practical level: by studying the everyday activities and interactions of creative individuals and communities (e.g., Ellström, 2010; Stanley et al., 2016), in practice, as they unfold.

Many social sciences have started to pay more attention to the everyday interactions of social beings - generally referred to as the "practice turn" - and using these everyday activities and interactions as a basis for theorization. Although focusing on everyday practice is attractive, the widespread adoption of practice-based research is partially inhibited by the overwhelmingly philosophical underpinnings of practice theories, relying strongly on philosophers and sociologists such as Bourdieu, Foucault, Giddens, and de Certeau (van der Hoorn \& Whitty, 2017; Whittington, 2006). Such a theoretical/philosophical approach, while pleasing to editors of top management journals, is not suited to all researchers, and is especially ill-suited for busy practitioners trying to grow their understanding of their everyday challenges. Luckily, there is another way.

Pitsis and colleagues (Clegg et al., 2006; Pitsis et al., 2003) and Hällgren (2007) offer examples of another, decidedly less theory-heavy way to study practice, by strongly focusing on specific, recurring phenomena and building generalizations and theorizations starting with these kernels. Hällgren's study uses the management of deviations in power station construction to great effect, while Pitsis and colleagues unearth their subject organization's recurring use of "endgames" as a central method of making sense of their task and context. Instead of conceptualizing practice at an abstract level, these authors take practice to the micro-level. In this article, I propose a similar, micro-level approach to studying creative communities' practice.

In the next section, I present my suggestion for studying creative communities by focusing on observing and understanding the social micro-interactions which not only facilitate creativities, but also - at heart - are what communal creativity is made of. While focusing on creativities instead of those rare results of creativity, which can rightly be called innovations, we also avoid the fallacy of focusing on a "select few". Thus, the focus of study is not individuals or specific teams but the entire communities within and between organizations that participate in creativity (see Cohendet \& Llerena, 2003).

The central benefits offered by the method presented in this article are twofold. First, the method offers a theoretically sound, comprehensive approach to studying social creative practice, which is based on one of the most acclaimed theories regarding creativity and organizational knowledge creation. Second, the method helps researchers and practitioners focus on those social interactions and social artefacts that play a key role in both utilizing previous creativities as well as facilitating further creativities.

\section{Developing the Method}

How can we study creative practice, especially as it is often part of a prolonged process, where most creativities happen between individuals? In order to not rely on post-facto rationalizations, we need to be able to observe creative communities in action. But access to the time and place only gets us half-way. To allow us to make pertinent observations, we need to know what to look for, know what kind of supporting data to treasure, and know how to interpret what we are observing, hearing, and reading. In short, we need to have a suitable epistemology and attendant research method. This is where the Practice Method for Studying Creative Communities (PMSCC) enters the picture.

"Epistemology" and "research method" - terms rarely used beyond academia - are valuable concepts to practitioners as well. An epistemology is an understanding of knowledge that helps to see a) what knowledge is and b) how "valid" knowledge can be obtained (Hirschheim, 1985). An epistemology (i.e., "What is creativity?"; "How can I learn about creativity?") thus informs the selection of a research method (i.e., "How do I go about trying to study creativity?"). These concepts are 


\section{A Practice Method for Studying Creative Communities}

\section{Pekka Buttler}

valuable because they define our ability to be where we need to be, to zero-in on relevant events, and to interpret and understand what we are observing in a meaningful way. As a corollary, should our epistemology and method be unsuitable, we might end up with partial, skewed, or even outright erroneous conclusions. Therefore, it is important that our epistemology and method be informed by the best theories available.

While the rationale behind the PMSCC is detailed in subsequent chapters, Table 1 below summarizes all the practical aspects of implementing the PMSCC in a research project. It is designed to be straightforward and uncomplicated to use, and while I recommend examination of the original theoretical bases (Nonaka \& Takeuchi, 1995; Polanyi, 1966), I will explain most relevant aspects of these aspects in the sections that follow.

\section{An epistemology of creative communities}

Although innovation and creativity are popular topics, and definitions and models abound, few offer a picture of the relationship between creativities and innovation that is more aware of social interaction and that is more longitudinal than the seminal work of Nonaka and Takeuchi. Working based on Polanyi's (1966) classification of knowledge into tacit and explicit, and using their extensive experience with Japanese industry, Nonaka and Takeuchi developed their models on knowledge conversions and innovation in organizations. First, Nonaka and Takeuchi (1995) identified four types of social "knowledge conversion" between tacit and explicit forms, then went on to note that knowledge aggregation is a cyclical, iterative process, where innovation is not the result of one individual's singular flash of brilliance, but rather the result of the creative social dynamics (see also Cummings et al., 2015).

Thus, the core of Nonaka and Takeuchi's theory of organizational knowledge creation is that all inventions are fundamentally based on social interactions between individuals, often facilitated through social artifacts (see Figure 1). Significantly, Nonaka and Takeuchi also see innovations being further refined through continuous/repeated iteration.

Table 1. Summary of the Practice Method for Studying Creative Communities, detailing data gathering methods, foci, purposes, and overarching framework

\section{Observation}

Interviews

\section{Documents}

- Longitudinally (over time) repeatedly

- Make notes or record (audio/video)
- As often as possible, as soon as possible

- Make notes or record (audio/video)
- Gather documents throughout research

- Make notes, take copies, photograph artefacts

\begin{tabular}{lll}
\hline Observe social interactions: & Interview participants: & Studydocuments: \\
\hline - Day-to-day work & $\bullet$ On all levels (designer, manager, & $\bullet$ To gain understanding of \\
- Meetings & client) & background \\
- Workshops & To unearth motivations and & To track progress \\
- Retreats & rationalizations & $\bullet$ To use as touchpoints in interviews \\
- Hands-on sessions & - Togain insight into thinking & and reports
\end{tabular}

Pay special attention to:

- Use of cognitive tools (metaphors, analogies, concepts, models, etc.)

- Social dynamic

- Knowledge sharing, integration and particularization
- Descriptions of ideas and insights, and their origins and initiators

- Individual accounts of social dynamic

- Rationalizations of knowledge conversions
- Progress (over time) of plans and design artefacts (e.g., prototypes)

- Formal rationalizations of choices and trade-offs made

- How inputs (briefs, feedback, etc.) affect creative work 


\section{A Practice Method for Studying Creative Communities}

\section{Pekka Buttler}
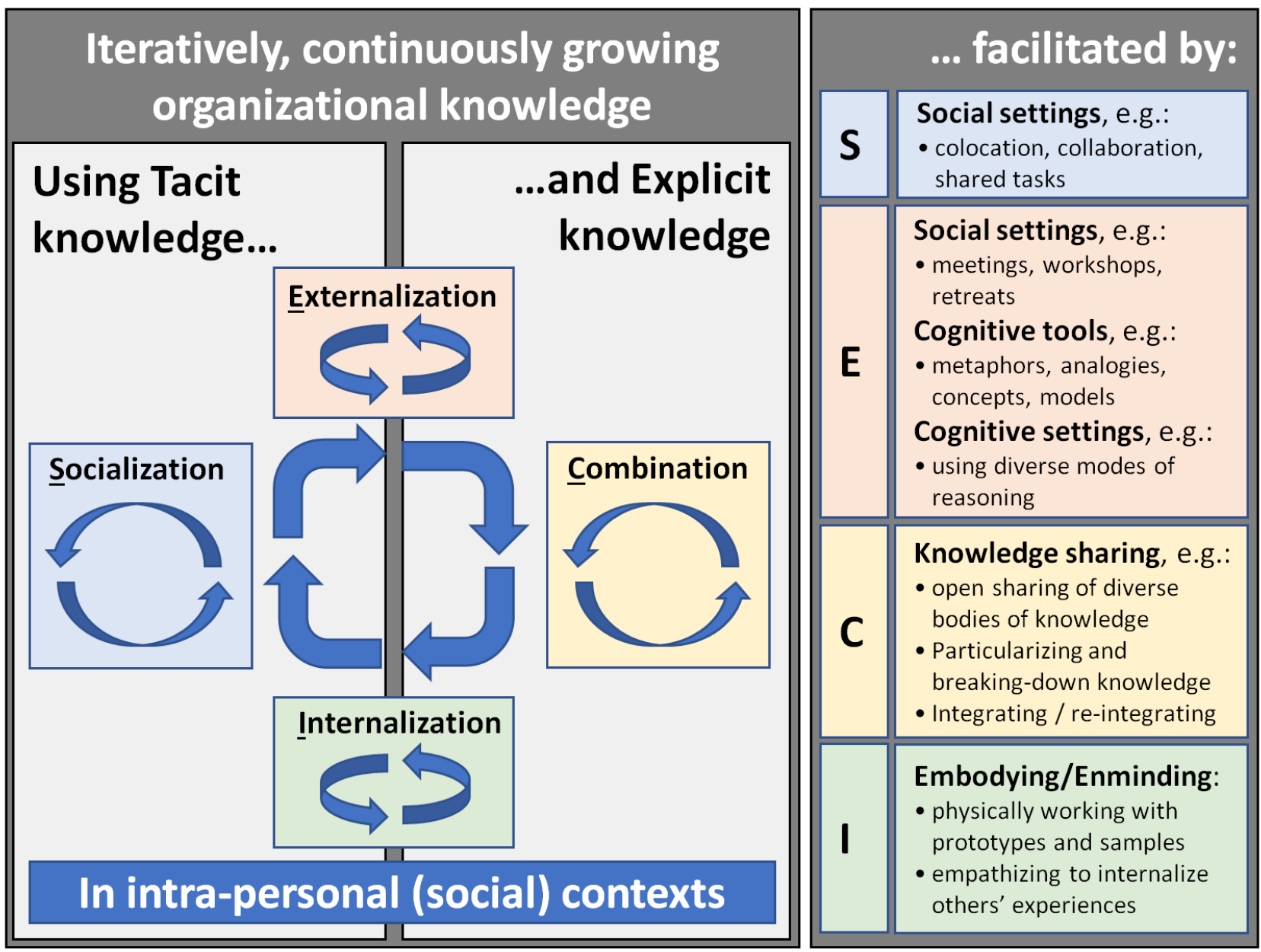

Figure 1. Core interactions and facilitators of organizational knowledge creation (based on Nonaka \& Takeuchi, 1995)

A theory - such as the one offered by Nonaka and Takeuchi - is "a coherent group of general propositions used as principles of explanation for a class of phenomena" (Webster's, 1996). In essence, it is a prediction saying "A and $\mathrm{B}$, in a situation like $\mathrm{C}$, results in $\mathrm{D}$ ". Interestingly, specific theories are not one-way relationships - they can also be turned around, creating a specific epistemology.

In this article, I therefore propose that these social activities and the facilitating social artefacts are the everyday micro-interactions that are the initial building blocks of all innovations and are thus "what you need to be looking at" in order to understand creative teamwork and to find the origins of innovations.

\section{Gathering data on creative communities}

Table 2 summarizes the terminologies used by Nonaka and Takeuchi, gives a short description of the entities (knowledges and interactions) involved. It also states potential facilitators, details researchers' central challenges regarding the entity, and proposes workable data gathering methods. Table 2 provides the theoretical foundation of the PMSCC, but additional points should be considered before actually applying the method in practice:

1. The multimodal data-gathering approach consisting of interviews, observations, and study of documents while demanding to the outside researcher - is easily doable for the inquisitive insider, who naturally can observe their colleagues, has access to relevant records, and can always chat with colleagues. A multimodal approach also facilitates constant triangulation.

2. Although knowledge on an entity might theoretically be attainable, no guarantees exist: you may ask - and you should - but you may not get answers. 


\section{A Practice Method for Studying Creative Communities}

\section{Pekka Buttler}

3. Nonaka and Takeuchi (1995) use the term "conversion", but conversion does not imply full translation (see also Nonaka \& von Krogh, 2009; Tsoukas, 2005), meaning that the part that can successfully be "converted" is always less than the entirety.

4. The model is inherently social: knowledge conversions take place between people, not within people.

5. Inside teams are often utterly dependent on inputs from the community, such as client needs and user feedback (see also Pellikka \& Ali-Vehmas, 2016). Thus, researchers should not focus too strongly on the team; instead, they should acknowledge the significance of the wider communities.

6. Finally, some of the method's targets are more salient (e.g., visible social artifacts, explicit knowledge), while others may be harder to observe. Although it certainly would be understandable if a researcher were to focus on these salient targets, such an implementation is risky: researchers might still be able to describe "what" but be none the wiser as to "why" or "how".

In summary, by focusing on two knowledge entities, four knowledge conversions, as well as the social facilitators (see Table 1 and Table 2), longitudinally (over time), researchers and practitioners can use the PMSCC to gain a wealth of knowledge about interactions in creative communities, how these help fuel creativities, and how these interactions over time aggregate into things we might call inventions, or even innovations.

\section{Applying the Method in Practice}

In this section, I will briefly describe the results of a research project that utilized the PMSCC. I present two vignettes showing how the different components of the method interact to facilitate new insights. Finally, I will summarize the central benefits offered by the PMSCC in the research project.

The vignettes offer brief glimpses of real-life cases I have been studying as part of a larger research project into the use of conceptual thinking in information technology projects. During this research, I have been working alongside teams in several Nordic organizations. In all cases, I have had the privilege of unencumbered access to both documents and people and have been observing interesting and revealing everyday creative and problem-solving activities. In order to gain such a deep level of access, I have committed to keeping all person- al and corporate data confidential. Thus, details on inventions have been omitted and all names mentioned in the vignettes have been fictionalized.

\section{Vignette 1: ExtenLibri}

I observed TechniGrafis - an IT consultancy participating in a project aimed at developing products and services for LibriGulo, a company offering literature to people with various disabilities. The project encompassed multiple parts, with one subproject, "ExtenLibri", aiming at coming up with new types of services to increase the potential reach of digital literature. Although TechniGrafis has extensive know-how in literature-related technologies, the company knew that service development and ideation - especially for audiences with disabilities - was not its forte.

Using its client base, TechniGrafis set up an ad-hoc workgroup containing both in-house resources (mostly technologists) and outside consultants to offer industry insights (especially with regards to usage patterns of literature). The project functioned on three levels - the inhouse team shared an office and met every day, the workgroup had meetings about once a week, and TechniGrafis met with LibriGulo roughly twice a month. Initially, the plan was for the outside consultants to offer inputs and potential ideas, which the in-house team would then "process" before being presented to LibriGulo for comments. In all, the ExtenLibri project ran for slightly over three months.

After an uninspiring beginning, the project began churning out a wealth of suggestions, comprising both incremental improvements as well as some genuinely novel concepts, with several of these being fed back into the other projects for further study. All parties agreed the ExtenLibri project had been successful - even surprisingly so.

Although a study of the project's inputs (initial briefs) and outputs (documented suggestions) would have easily shown the apparent success of the project, the actual mechanisms behind that success would have remained elusive. Being able to observe the various workshops and meetings enabled me to elucidate a critical component of the creative process - the combining of different bodies of explicit knowledge (Nonaka \& Takeuchi, 1995). In particular, this combination was obvious in the intrapersonal interactions of TechniGrafis employees (i.e., technologists, some of which admitted to not regularly reading anything but technical manuals); their outside consultants, who were able to describe psychological and social effects related to 


\section{A Practice Method for Studying Creative Communities}

\section{Pekka Buttler}

Table 2. Knowledge entities, their nature, their knowledges, and a practical approach to gaining data

\begin{tabular}{|c|c|c|c|c|}
\hline $\begin{array}{l}\text { Entity (Knowledge } \\
\text { / knowledge } \\
\text { conversion) }\end{array}$ & Nature of Entity & $\begin{array}{l}\text { Facilitators } \\
\text { (for conversions) }\end{array}$ & $\begin{array}{l}\text { Entity's Research- } \\
\text { Relevant } \\
\text { Characteristics }\end{array}$ & $\begin{array}{l}\text { Data-Gathering Methods for } \\
\text { Capturing Knowledge of } \\
\text { Entity }\end{array}$ \\
\hline $\begin{array}{l}\text { Tacit knowledge } \\
\text { (Nonaka \& } \\
\text { Takeuchi, 1995; } \\
\text { Polanyi, 1966) }\end{array}$ & $\begin{array}{l}\text { Personal and contextual } \\
\text { knowledge embedded in } \\
\text { the individual's body } \\
\text { (embodied) or corpus of } \\
\text { knowledge }\end{array}$ & N/A & $\begin{array}{l}\text { No direct way of capturing } \\
\text { others' tacit knowledge. } \\
\text { Indirectly accessible } \\
\text { through socialization or as } \\
\text { externalized explicit } \\
\text { knowledge. }\end{array}$ & $\begin{array}{l}\text { - Directly: None. } \\
\text { - Indirectly: Limited. Through } \\
\text { observation(via socialization) } \\
\text { or interviews (via } \\
\text { externalization). }\end{array}$ \\
\hline $\begin{array}{l}\text { Socialization } \\
\text { (Nonaka \& } \\
\text { Takeuchi, 1995) }\end{array}$ & $\begin{array}{l}\text { Social knowledge } \\
\text { conversion from tacit to } \\
\text { tacit knowledge through } \\
\text { observation, imitation, and } \\
\text { practice (experience) - } \\
\text { often without use of formal } \\
\text { language }\end{array}$ & $\begin{array}{l}\text { Social settings, e.g.: } \\
\text { - colocation } \\
\text { - collaboration } \\
\text { - shared tasks }\end{array}$ & $\begin{array}{l}\text { Whether socialization } \\
\text { happens is not observable } \\
\text { (even though the social } \\
\text { setting for it might be). } \\
\text { Indirectly, a researcher } \\
\text { may gain information on } \\
\text { socialization viainterviews } \\
\text { or through (preferably) } \\
\text { close observation. }\end{array}$ & $\begin{array}{l}\text { - Directly: None. } \\
\text { - Indirectly: Primarily through } \\
\text { interviews (via externalization) } \\
\text { and secondarily through } \\
\text { observation (via socialization). }\end{array}$ \\
\hline $\begin{array}{l}\text { Externalization } \\
\text { (Nonaka \& } \\
\text { Takeuchi, 1995) }\end{array}$ & $\begin{array}{l}\text { Social knowledge } \\
\text { conversion from tacit to } \\
\text { explicit knowledge, mostly } \\
\text { indirectly, through } \\
\text { "metaphors, analogies, } \\
\text { concepts hypotheses, or } \\
\text { models" }\end{array}$ & $\begin{array}{l}\text { Social settings, e.g.: } \\
\text { - Meetings } \\
\text { - Workshops } \\
\text { - Retreats } \\
\text { Cognitive tools, e.g.: } \\
\text { - metaphors } \\
\text { - analogies } \\
\text { - concepts } \\
\text { - models, etc. } \\
\text {...while using several } \\
\text { modes of reasoning } \\
\text { (cognitive setting) }\end{array}$ & $\begin{array}{l}\text { Externalization is both a } \\
\text { social activity and part of it } \\
\text { (expressed explicit } \\
\text { knowledge) is clearly } \\
\text { visible. Also, aspects of the } \\
\text { social dynamic are } \\
\text { observable. What happens } \\
\text { before the expression of } \\
\text { externalized knowledge is } \\
\text { not observable, however, } \\
\text { and can only be reached } \\
\text { through interviews. }\end{array}$ & $\begin{array}{l}\text { - Directly: Through observation } \\
\text { of social dynamic and } \\
\text { expressed explicit knowledge } \\
\text { during social events. } \\
\text { - Indirectly: Through interviews } \\
\text { to gain understanding of } \\
\text { individual mental dynamic } \\
\text { (metaphors, analogies, } \\
\text { conceptual work). }\end{array}$ \\
\hline $\begin{array}{l}\text { Explicit knowledge } \\
\text { (Nonaka \& } \\
\text { Takeuchi, 1995) }\end{array}$ & $\begin{array}{l}\text { Knowledge of a separate, } \\
\text { disembodied, particular, } \\
\text { and detailed nature, but } \\
\text { still owned by a subject. } \\
\text { When converted into } \\
\text { information, easy to copy } \\
\text { and transmit. }\end{array}$ & $\mathrm{N} / \mathrm{A}$ & $\begin{array}{l}\text { Explicit knowledge (as } \\
\text { such) is, in theory, } \\
\text { perfectly accessible } \\
\text { throughinterviews. } \\
\text { Information, especially } \\
\text { when in the form of } \\
\text { documents can be studied } \\
\text { directly. }\end{array}$ & $\begin{array}{l}\text { - Directly: As information, } \\
\text { through direct study of } \\
\text { documents (records, plans, } \\
\text { drawings, sketches etc.) } \\
\text { - Indirectly: As explicit } \\
\text { knowledge through interviews. }\end{array}$ \\
\hline $\begin{array}{l}\text { Combination } \\
\text { (Nonaka \& } \\
\text { Takeuchi, 1995) }\end{array}$ & $\begin{array}{l}\text { Social knowledge } \\
\text { conversion from explicit to } \\
\text { explicit, combining } \\
\text { different corpora of explicit } \\
\text { knowledge creating new } \\
\text { knowledge compounds } \\
\text { (and particulars) }\end{array}$ & $\begin{array}{l}\text { - Bringing different } \\
\text { corpora of explicit } \\
\text { knowledge together and } \\
\text { sharing } \\
\text { - Breaking down or } \\
\text { operationalizing } \\
\text { concepts } \\
\text { - Particularizing } \\
\text { knowledge } \\
\text { - Integrating (or re- } \\
\text { integrating) knowledge }\end{array}$ & $\begin{array}{l}\text { Combination is a candid, } \\
\text { social activity, where both } \\
\text { the activity and knowledge } \\
\text { (explicit, expressed) are } \\
\text { openly presented. } \\
\text { Information on } \\
\text { background processes can } \\
\text { be gained through } \\
\text { interviews. }\end{array}$ & $\begin{array}{l}\text { - Directly: Through observation } \\
\text { of social dynamic and } \\
\text { expressed explicit knowledge } \\
\text { during events of combination. } \\
\text { - Indirectly: Through interviews } \\
\text { to gain understanding of } \\
\text { individual's mental dynamic. }\end{array}$ \\
\hline $\begin{array}{l}\text { Internalization } \\
\text { (Nonaka \& } \\
\text { Takeuchi, 1995) }\end{array}$ & $\begin{array}{l}\text { Social knowledge } \\
\text { conversion from explicit to } \\
\text { tacit, embedding explicit } \\
\text { knowledge into } \\
\text { individual's body or corpus } \\
\text { of knowledge, using bodily } \\
\text { experience, simulations } \\
\text { and empathy }\end{array}$ & $\begin{array}{l}\text { - Embodying: Through } \\
\text { physical experience } \\
\text { (manipulation, trying) } \\
\text { with mock-ups, } \\
\text { prototypes, samples. } \\
\text { - Enminding: Through } \\
\text { empathy }\end{array}$ & $\begin{array}{l}\text { Internalization is not } \\
\text { observable. Although } \\
\text { internalization is socially } \\
\text { enabled and often } \\
\text { conscious, the result (new } \\
\text { tacit knowledge) is } \\
\text { personal. }\end{array}$ & $\begin{array}{l}\text { - Directly: None } \\
\text { - Indirectly: Through } \\
\text { observation(via socialization) } \\
\text { and interviews (via subject's } \\
\text { externalization). }\end{array}$ \\
\hline
\end{tabular}




\section{A Practice Method for Studying Creative Communities}

\section{Pekka Buttler}

perusal of literature in general; and the representatives of LibriGulo, who were able to both illustrate the typical limitations encumbering users with various types of disability as well as the motivations driving such readers.

Thereafter, I focused on trying to unearth the origins of (what we deemed to be) the 10 most significant novel insights. Thanks to the full access provided to me, I was able to backtrack these novel ideas to when they were first voiced, thus allowing me to subsequently focus my interviews on trying to further trace back these insights to their origins. While I am unable to fully account for all the origins, I was able to unearth several interesting and fortuitous chains of events. In one case, a TechniGrafis employee told me how they had come to visit their mother at the retirement home and, finding her in the library with a heavy magnifying device in her hand (i.e., one that is not easily carried), came to "the realization that elderly can go to great lengths in order to read". In another case, a TechniGrafis project manager recounted how they had - after reading their kids a bedtime story come to the dual realizations that, children and the elderly suffer many of the same limitations as readers - albeit due to different mechanisms. They also reflected on how the social activity of reading to children might translate to the elderly - an idea which resulted in a campaign for people to visit retirement homes as "readers". Besides these kinds of situations where individuals have not been aware of actively thinking about the project, there were also accounts of "sudden, surprising flashes of brilliance", which could be plausibly traced back to recent subconscious priming events. For example, the technologist who surprised themself by suggesting the idea of using speech synthesis to facilitate an on-demand audiobook service only later recalled recently witnessing a situation where their children were playing with an online speech synthesis tool.

Finally, I was also able to identify practices that seem to have been conducive to furthering the team's creativity. First, in addition to the daily meetings at the office, the TechniGrafis team instigated a "project lunch" - a weekly lunch meeting during which the team went to a restaurant (instead of the office cafeteria). Although the lunch was initially intended purely for team building, it quickly morphed into a "meeting without paper". Several team members said that they - feeling in many ways out of their depth, and thus apprehensive in regular meetings - felt freer to explore options. In effect, the project lunches lowered thresholds for participation. Subsequently, an analysis showed a disproportionate percentage of contributions being first aired during these lunches.
Second, one technologist had suggested a "utopia box" - a cardboard box in the office kitchenette where team members were encouraged to anonymously deposit outlandish dreams related to the project's remit, with the only precondition being that each utopian suggestion must start with "Wouldn't it be splendid if...". Although all of the 46 utopians suggestions logged (and subsequently posted on the team "HQ" wall and discussed during regular meetings) were considered outlandish, many contributed in some way to subsequent, more practical ideas.

Interviews with staff revealed interesting insights about both cases (i.e., project lunches and the utopia box). Although many felt that such threshold-lowering initiatives had improved their willingness to share ideas and insights and applauded the measures, several others felt that the initiatives had failed in making people feel safe to share. One architect recounted a team recreation event, where some team members had been openly discussing the faults of some proposals and speculating derisively on who might be the ideas' progenitor. Thus, it would seem to be important to not only create structures that support creativities, but to also engender a culture supportive of creativities.

Although the ExtenLibri project produced many ideas, and a significant number of them were deemed as having economic potential, only time will tell whether these will amount to viable services.

\section{Vignette 2: Online Content Service Modernization}

I also observed the cooperation of VenefiSoft - a midsize software company - and CogniVenda - a publishing company. CogniVenda had been at the vanguard of using information technology to capitalize on their intellectual property, moving into online publishing at an early stage. From 2017-18, CogniVenda's online service for subscribers accessing their intellectual property was rapidly becoming technologically outdated. CogniVenda contacted VenefiSoft (the creators of the original online service) to thoroughly modernize the online service, a project hereafter referred to as Online Content Service Modernization (OCSM).

From the beginning of OCSM, VenefiSoft and CogniVenda decided on an agile, incremental development process, allowing the service's modules to be implemented and rolled-out sequentially. Also, with CogniVenda's help, VenefiSoft enrolled a handful of the online service's corporate clients (referred to as "key users") to act as test users for newly implemented modules. As CogniVenda demanded the right to "ok" each 


\section{A Practice Method for Studying Creative Communities}

\section{Pekka Buttler}

module for release to key users, I was also able to observe the dynamics between the three tiers of involved parties: contractor, client, and users.

Again, even a quick comparison between initial project objectives and the result would have shown the project to be a resounding success but being able to unearth how that came to be necessitated being able to observe the seemingly mundane day-to-day activities. Although my observation of the project uncovered many interesting findings, this vignette focuses on two elements: the benefits of an iterative, participative design process and the potential of true outsider viewpoints.

As VenefiSoft had both the requisite technological know-how and a detailed knowledge of the intellectual property in question, most of the initial implementations of modernized modules met with direct approval from CogniVenda. However, once these modules were made available to key users, they overwhelmingly proposed not only corrections, but also further improvements (e.g., user-interface improvements, new features). As the modules varied greatly in size and significance, quantitative metrics would not tell the whole story. Suffice it to say that: a) key users were more demanding and constructive than CogniVenda; b) CogniVenda was generally impressed by the quality and quantity of feedback key users produced; c) subsequent revised implementations of some modules generated a spate of new suggestions for improvements. Thus, thanks to the iterative approach, modules kept improving with each iteration and each new iteration was likely to engender new suggestions.

This process of incremental improvements indicated two key aspects. First, the process exemplified what Nonaka and Takeuchi (1995) propose to be typical of externalization and internalization: that externalization (finding ways to express what is tacitly known) is far from simple and often succeeds only after time, and that internalization often necessitates working with samples (e.g., testing, prototypes). Second, the prolonged iterative process - working through the cycle of externalization, combination, internalization, and socialization - has great potential to lead to growing organizational knowledges as manifested through improved solutions.

Also, it is quite obvious that including the key users in the project from the beginning was highly beneficial through the addition of a third knowledge base: besides the technical know-how provided by VenefiSoft and the economic know-how provided by CogniVenda, key users were able to contribute with hands-on knowledge of actual real-life needs.

Finally, it also turned out that there was a fourth significant "knowledge base". Although each of the three parties (CogniVenda, VenefiSoft, and key users) made clear contributions to the process, they were also restricted by their knowledge of the existing system: an overwhelming majority of changes and suggestions were incremental in nature, while very few of the initiatives can be characterized as radical. Subsequent detailed study and interviews showed that all radical suggestions came from only three people - all without detailed prior knowledge of the existing system. Not surprisingly, these radical suggestions were not all met with approval, but those that were have subsequently been seen as highly successful. Thus, it would seem that, although knowledge and experience are valuable, ignorance also may be beneficial. A significant question would thus be whether the parties could have benefited from canvassing true outsider viewpoints more systematically.

The previous technological implementation of CogniVenda's online service was live for nine years. Whether the modernized service will outlast its predecessor is uncertain, but all parties agree that the potential exists.

\section{Practical Benefits of the Method}

Besides unencumbered access to subjects, the project has also benefited from a method that enables the researcher to focus on the fundamental micro-interactions and to conceptualize and make sense of what is perceived, while simultaneously also showing where to dig deeper. As such, the data gathering portrayed in the vignettes indicate interesting areas for further study: the significance of including various, diverging bodies of knowledge; the potential offered by an extended, iterative ideation process; and several ways to foster social creativity through lowering individuals' thresholds and offering multiple ways of giving input.

The data gathering has also shown that not all ideas make it. I witnessed numerous creativities that were not incorporated into the final result. Some of these ideas were outright impractical, whereas other were superseded by ideas felt to be superior, and some ideas themselves engendered new ideas superseded them. Based on these observations, I feel it important to note that ideas should not be judged by whether they "make it", but by how they contribute to the community's creative culture. 


\section{A Practice Method for Studying Creative Communities}

\section{Pekka Buttler}

Although the vignettes reproduce only a small portion of the data gathering thus far, and as such do not offer nearly enough data to allow one to draw any generalizable conclusions, they nevertheless attest to the potential power of a practice-based research approach, through a combination of a) allowing the researcher to focus on the all-important micro-interactions; b) allowing the researcher to fit otherwise unconnected observations into a conceptual model connecting micro-level creativities with macro-level results (potential innovations); c) discover cognitive discontinuities through being able to constantly triangulate between what the researcher perceives (observations), how the participants explain themselves (interviews), and how things are codified (records), thus also highlighting areas of special interest; and d) working back-and-forth between nascent theorizations and real-life data. Thereby, the research method allows researchers to act in a continuous cycle of theorization and theory-testing.

\section{Conclusion}

The PMSCC offers researchers a valuable tool: not only does it show where one needs to be, but it also helps one focus on interactions that would otherwise easily remain unseen. Furthermore, as the PMSCC conceptualizes these interactions in a wider framework, one is not blinded by the abundance of details. Instead, one can clearly see the myriad creativities interact, foster new creativities, and help fuel the entire creative process. It is my opinion that the PMSCC has allowed me to gain greater insights and understanding of these creative processes than any unimodal research method would have allowed. Also, having had the pleasure to see these creativities unfold in front of my eyes, I feel privileged compared to researchers having to try to reconstruct chains of events in hindsight.

The novelty of the PMSCC is not in the actual data gathering methods it employs, but in how they are focused and integrated. The PMSCC differs from conventional, general research methods through the synergistic interplay between a multimodal data gathering setup, a needle-sharp focus on the micro-interactions through which organizations generate ideas and (hopefully) innovations, while simultaneously seeing creative instances as part of a prolonged process of incremental development. The power of the PMSCC to explain otherwise opaque processes through real-time access to creativities also indicates its main weakness: the PMSCC is strictly a real-time method and cannot be used retroactively.

timreview.ca
The PMSCC also is a very practitioner-friendly method. As an external researcher, I had to work hard and long to gain the level of access I enjoyed. The inquisitive practitioner, on the other hand, has a much easier task: they start where it took me weeks - even months - to reach. What the practitioner then needs, in order to make worthwhile observations and gain new insights, is a suitable and powerful research method - something I hope to have hereby contributed to.

\section{Acknowledgements}

I would like to thank the Finnish Foundation for Economic Education for its support in funding this research. Also, throughout the research project, I have enjoyed unencumbered access to my subjects, and a great deal of thanks goes to the informants and informant organizations, who have allowed me to sit in on their everyday activities and have done their best to answer my questions.

\section{About the Author}

Pekka Buttler, M.Sc. (Econ), is a doctoral student at the Hanken School of Economics in Helsinki, Finland, where he is researching conceptual design in IT projects. His other academic interests range from leading knowledge work to software business management. Besides research, Pekka involves himself in teaching and consulting by utilizing his more than 15 years of experience within the IT industry.

\section{References}

Anderson, N., de Dreu, C. K. W., \& Nijstad, B. A. 2004. The Routinization of Innovation Research: A Constructively Critical Review of the State-of-the-Science. Journal of Organizational Behavior, 25(2): 147-173.

https://doi.org/10.1002/job.236

Clegg, S. R., Pitsis, T. S., Marosszeky, M., \& Rura-Polley, T. 2006. Making the Future Perfect: Constructing the Olympic Dream. In D. Hodgson \& S. Cicmil (Eds.), Making Projects Critical: 265-294. Houndmills, UK: Palgrave Macmillan.

Cohendet, P., \& Llerena, P. 2003. Routines and Incentives: The Role of Communities in the Firm. Industrial and Corporate Change, 12(2): 271-297.

https://doi.org/10.1093/icc/12.2.271

Cohendet, P., \& Simon, L. 2015. Introduction to the Special Issue on Creativity in Innovation. Technology Innovation Management Review, 5(7): 5-13.

http://doi.org/10.22215/timreview/909 


\section{A Practice Method for Studying Creative Communities}

\section{Pekka Buttler}

Cummings, S., Bilton, C., \& ogilvie, dt. 2015. Toward a New Understanding of Creative Dynamics: From One-Size-Fits-All Models to Multiple and Dynamic Forms of Creativity. Technology Innovation Management Review, 5(7): 14-24. http://doi.org/10.22215/timreview/910

Ellström, P.-E. 2010. Practice-Based Innovation: A Learning Perspective. Journal of Workplace Learning, 22(1/2): 27-40. https://doi.org/10.1108/13665621011012834

European Commission. 2013. Developing the Creative and Innovative Potential of Young People through Non-Formal Learning in Ways that are Relevant to Employability. Brussels: European Commission.

http://ec.europa.eu/assets/eac/youth/library/reports/creativepotential_en.pdf

Forde, A. N., \& Fox, M. S. 2016. A Proposed Approach for Idea Selection in Front End of Innovation Activities. Technology Innovation Management Review, 6(8): 48-55. http://doi.org/10.22215/timreview/1011

Hirschheim, R. A. 1985. Information Systems Epistemology: An Historical Perspective. In R. D. Galliers (Ed.), Information Systems Research: Issues, Methods and Practical Guidelines: 28-60. Oxford: Blackwell Scientific Publishers.

Hällgren, M. 2007. Beyond the Point of No Return: On the Management of Deviations. International Journal of Project Management, 25(8): 773-780.

https://doi.org/10.1016/j.ijproman.2007.05.005

Intergovernmental Panel on Climate Change. 2005. IPCC Special Report on Carbon Dioxide Capture and Storage. Cambridge, UK: Cambridge University Press.

https://www.ipcc.ch/pdf/special-

reports/srccs/srccs_wholereport.pdf

Lashinsky, A. 2017. How CEO Marc Benioff Drives Relentless Forward Thinking at Salesforce. Fortune, October 19, 2017. Accessed October 1, 2018:

http:/ / fortune.com/2017/10/19/salesforce-marc-benioffleadership/

Nonaka, I., \& Takeuchi, H. 1995. The Knowledge-Creating Company: How Japanese Companies Create the Dynamics of Innovation. New York: Oxford University Press.

Nonaka, I., Toyama, R., \& Hirata, T. 2008. Managing Flow - A Process Theory of the Knowledge-Based Firm. Houndmills, UK: Palgrave MacMillan.

Nonaka, I., \& von Krogh, G. 2009. Perspective-Tacit Knowledge and Knowledge Conversion: Controversy and Advancement in Organizational Knowledge Creation Theory. Organization Science, 20(3): 635-652.

https://doi.org/10.1287/orsc.1080.0412

Pellikka, J., \& Ali-Vehmas, T. 2016. Managing Innovation Ecosystems to Create and Capture Value in ICT Industries. Technology Innovation Management Review, 6(10): 17-24. http://doi.org/10.22215/timreview/1024

Pitsis, T. S., Clegg, S. R, Marosszeky, M., \& Rura-Polley, T. 2003. Constructing the Olympic Dream: A Future Perfect Strategy of Project Management. Organization Science, 14(5): 574-590. https://doi.org/10.1287/orsc.14.5.574.16762
Polanyi, M. 1966. The Tacit Dimension. New York: Doubleday \& Co.

Prime Minister's Office Finland. 2015. Finland, A Land of Solutions Strategic Programme of Prime Minister Juha Sipila's Government. Helsinki: Edita Prima.

http://valtioneuvosto.fi/documents/10184/1427398/Ratkaisujen+ Suomi_EN_YHDISTETTY_netti.pdf

Runco, M. A. 2014. Creativity - Theories and Themes: Research, Development, and Practice (2nd ed.). London: Academic Press.

Serrat, O. 2017. Knowledge Solutions. Singapore: Springer. https://doi.org/10.1007/978-981-10-0983-9

Stanley, T., Matthews, J., \& Davidson, P. 2016. Insights from Stimulating Creative Behaviours in a Project-Based Organization Team. Technology Innovation Management Review, 6(4): 26-33. http://doi.org/10.22215/timreview/979

Tsoukas, H. 2005. Do We Really Understand Tacit Knowledge? In S. Little \& T. Ray (Eds.) Managing Knowledge: An Essential Reader (2nd ed.): 107-126. London: Sage.

UK Government Office for Science. 2017. Technology and Innovation Futures 2017. London: UK Government Office for Science. https://assets.publishing.service.gov.uk/government/uploads/syst em/uploads/attachment_data/file/584219/technologyinnovation-futures-2017.pdf

Valgeirsdottir, D., \& Onarheim, B. 2017. Realistic Creativity Training for Innovation Practitioners: The Know-Recognize-React Model. Technology Innovation Management Review, 7(6): 5-15. http://doi.org/10.22215/timreview/1080

van der Hoorn, B., \& Whitty, S. J. 2017. The Praxis of "Alignment Seeking" in Project Work. International Journal of Project Management, 35(6): 978-993. https://doi.org/10.1016/j.ijproman.2017.04.011

Webster's. 1996. Webster's Encyclopedic Unabridged Dictionary of the English Language. Bexley, OH: Gramercy Books.

West, M. A. 2002. Sparkling Fountains or Stagnant Ponds: An Integrative Model of Creativity and Innovation Implementation in Work Groups. Applied Psychology: An International Review, 51(3): 355-424.

https://doi.org/10.1111/1464-0597.00951

Whittington, R. 2006. Completing the Practice Turn in Strategy Research. Organization Studies, 27(5): 613-634. https://doi.org/10.1177/0170840606064101

Citation: Buttler, P. 2018. A Practice Method for Studying Creative Communities. Technology Innovation Management Review, 8(11): 22-31. http://doi.org/10.22215/timreview/1197

Keywords: creativity, innovation, teamwork, communities, research method, practice 


\title{
Information Security Best Practices: First Steps for Startups and SMEs

\author{
Urpo Kaila and Linus Nyman
}

\author{
"( Many hands make light work. ") \\ John Heywood (1497-1580) \\ Writer, musician, and composer
}

\begin{abstract}
This article identifies important first steps toward understanding and implementing information security. From the broad selection of existing best practices, we introduce a lightweight yet comprehensive security framework with four useful first steps: identifying assets and risks; protecting accounts, systems, clouds, and data; implementing a continuity plan; and monitoring and reviewing. This article is intended primarily for startups and less mature companies, but it is likely to be of interest to any reader seeking an introduction to basic information security concepts and principles as well as their implementation.
\end{abstract}

\section{Introduction}

Consider the scale of malware threats facing a business today. Hundreds of thousands of new malicious files are detected every single day, and almost a third of user computers encountered an online malware attack in 2017 (Kaspersky Lab, 2017). Tens of thousands of phishing sites are created each day (Webroot, 2017). Ransomware, a form of malware that encrypts files on a computer demanding a ransom in exchange for (the possibility of) getting the decryption key, has, according to the European Union's law enforcement organization Europol, "eclipsed most other global cybercrime threats" (Europol, 2017a, see also 2017b). In June of 2017, shipping giant Moller-Maersk was hit by ransomware. Maersk's losses, according to a statement by CEO Soren Skou, were estimated to reach up to $\$ 300$ million USD (Novet, 2017). The attack wreaked such devastation on the company's IT infrastructure that Maersk employees, with both company email and address systems down, had to rely on using WhatsApp on their personal phones to do their work (Thomson, 2017). Two things are worth noting about the specific form of ransomware Maersk was infected with. First, it was designed to be self-replicating, meaning that every infected computer immediately started looking for new machines to infect. Second, researchers believe the ransomware in question, called NotPetya, was designed not for financial gain, but rather "to spread fast and cause damage" (Mathews, 2017), with little hope for companies of getting their data back even if they paid the ransom (Burton, 2017).
However, malware is just one of many IT-related risks companies face. The abundance of Internet-connected computers in the array of devices known as the Internet of Things has introduced a host of new risks and vulnerabilities (Hypponen \& Nyman, 2017). Consider the peculiar case of a North American casino where attackers used an Internet-connected thermometer in a fish tank in the casino lobby to gain access to the casino's network and steal a database containing the casino's highroller list (Williams-Grut, 2018). Data breaches can carry a high cost both financially as well as to a company's reputation, as Yahoo! experienced first-hand after news broke, in the middle of a corporate merger, that all 3 billion existing Yahoo! accounts had been compromised (Oath, 2017).

As the first author has shown in a previous paper (Kaila et al., 2011), by embedding security in normal operations in a systematic but practical way, a company can easily mitigate many daily cybersecurity risks. However, with all the work involved in starting or running a business, it may seem overwhelming to also find the time to stay informed about the constant stream of news stories about new vulnerabilities, data breaches, and companies getting "hacked" or falling victim to phishing or other online scams. In the face of so many threats, it can be hard to know where to start.

Security professionals have, over the decades, established a number of best practice frameworks and standards, such as the NIST Cybersecurity Framework (NIST, 


\section{Information Security Best Practices: First Steps for Startups and SMEs}

\section{Urpo Kaila and Linus Nyman}

2018a), the OWASP Security Knowledge Framework (OWASP, 2015), and the ISO/IEC 27001 standard (ISO, 2013), to help secure companies and their systems. Although such standards present comprehensive security frameworks, they can be prohibitively cumbersome to a startup or an SME looking to take their first steps towards implementing information security practices. For example, we once met a small software company developing innovative services for university students. This company wished to obtain from the universities limited access to student data to authenticate the students. However, a requirement to grant access was compliance with national information security requirements. Unfortunately, the software company found that the security framework was just so abstract and massive that they withdrew their request. Furthermore, adoption of adequate tools and best practices for security seems often to be constrained by vast and overly complex advice (Renaud, 2016), user interfaces, or requirements and frameworks. An iconic and striking description of the dilemma was presented in an article showing the poor user interface design of a specific version of the PGP encryption client software (Whitten \& Tygar, 1996). Security developers had been so focused on theoretical aspects of cryptography that they had failed to communicate the basic concepts of the tool to the users.

This article's first author is Head of Security for the Finnish IT Center for Science (CSC; csc.fi/en) and has spent decades in the field of security, with much of that time focused on developing, implementing, and reviewing security best practices. Our aim with this article is to show how it is possible to implement a lightweight yet fully functional adaption of complex security frameworks mainly intended for large and mature organizations with existing management and compliance governance systems. This article is not intended to be an exhaustive list of all useful best practices; instead, we present an introductory overview of the topic, focusing on a few practices to serve as a starting point for companies who want to take their first steps towards implementing security best practices. Our view and our contribution with this article is based on decades of practice in the field of information security, where we have generally seen success from compact and focused approaches to setting up information security and failure from overly sweeping or too product-oriented approaches to developing security. Our presentation is based on the classical quality circle of "plan - do check - act" (PDCA; wikipedia.org/wiki/PDCA), which is also the foundation for the more formal frameworks based on security governance.

We want to show how a startup or SME can adapt the best security practices in a comprehensive but lightweight manner. To know from where to start, how to continue, and when to check, managers need to have a frame of reference - a security framework - to see the big picture. In the United States, the National Institute of Standards and Technology (NIST; nist.gov) publishes the Special Publication (SP) 800 series (NIST, 2018b), which presents well-known guidelines and recommendations for the computer security community. The NIST guidelines are of high quality but quite ample. The NIST security framework identifies five stages for security operations: identify, protect, detect, respond, and recover. Here, we present best practices in a similar way, as a series of first steps, but in a more lightweight format aimed at those who are just becoming familiar with the topic. We also see that some advice presented in previous papers (e.g., Rees, 2010) could benefit from being updated to reflect the current IT environments of SMEs and startups, which are heavily based on cloud services and outsourced services.

At its most fundamental level, information security is about awareness. It is about knowing what to protect and how to protect it. And it is about knowing what to do and when, because, despite our best efforts, things will go wrong. The remainder of the article addresses these very topics as a series of practical steps companies can take. First, we discuss identifying assets and risks. Then, we address some critical assets to protect: accounts, systems, clouds, and data. This section also includes examples and suggestions for protecting those assets. We then cover the importance of having a continuity plan, which is essentially a guide to help organizations prepare and respond to various worst-case scenarios. Finally, we discuss the significance of monitoring and review and conclude with a list of recommended reading.

This article is primarily intended for readers with either no experience or very limited experience in information security. Our goal is for the article to be particularly useful for owners or managers of small companies who have not yet implemented security-related practices. The article serves as a general introduction to the topic and may therefore also be of interest to readers seeking a general understanding of security best practices and their implementation. 


\section{Information Security Best Practices: First Steps for Startups and SMEs}

\section{Urpo Kaila and Linus Nyman}

\section{Step 1. Identify Your Assets and Risks}

Managers often think of information security as a question of purchasing security-related products or services. While those are important considerations, they should come later. What you need in order to get started with implementing information security is not a credit card but rather a pen and paper. The first step in implementing information security is, quite simply, identifying what to secure. While this may sound trivial, it is perhaps the most difficult, and most overlooked, of all the steps. In our experience, when we have asked managers what their companies most important assets are, few have had ready answers.

In the past, identifying a company's assets and risks was often a more straightforward exercise. Where previously companies might have commonly processed a resource into a refined version of that resource - say, wood to lumber - many companies today process information rather than some physical resource. Listing not just the physical resources and risks to them, but also the "invisible", tacit knowledge, assets, and risks is less straightforward but no less important. Your assets may include a service you provide to your customers or the systems and people who make it possible for you to provide it.

A very clear and understandable, albeit simplified presentation of the relationship between threats, risks, controls, and assets can be found in the OWASP CISO AppSec Guide: Criteria for Managing Application Security Risks (OWASP, 2013). Figure 1 shows how threat agents can use attack vectors to exploit security weaknesses that can and should be mitigated with security controls to avoid, or at least reduce, technical and busi- ness impact. A hacker, using freely available exploit tools to gain access to a system with outdated software could cause negative technical and business impacts if access is not properly restricted by a firewall, for example.

There are three key concepts that form a useful foundation for your thinking about and work with implementing information security: confidentiality, integrity, and availability (sometimes referred to as "the CIA triad"). Confidentiality refers to protecting data from being accessed by unauthorized viewers. Integrity refers to maintaining the accuracy and consistency of data over its lifetime. Availability, as the name implies, refers to data being available when needed. At times, there are some challenging balancing acts involved in these key concepts, like the one between confidentiality and availability: how best to ensure everyone who needs access has access, without granting access to those who should not have it.

The output of this first step should be a list detailing assets to be protected and the primary risks to these assets. The goal is not to list every conceivable risk. Rather, it is to list the primary risks you see regarding the key resources you have identified as requiring protection. For example, one way to approach this step is by asking yourself: What IT-related events or mishaps, related to each individual asset, would make our customers and other stakeholders lose trust in our company?

Putting together this list will be beneficial for several reasons. One reason is that it will help you clarify your own knowledge and thinking regarding your company's information security. For any company with customers based in the European Union (EU), another significant

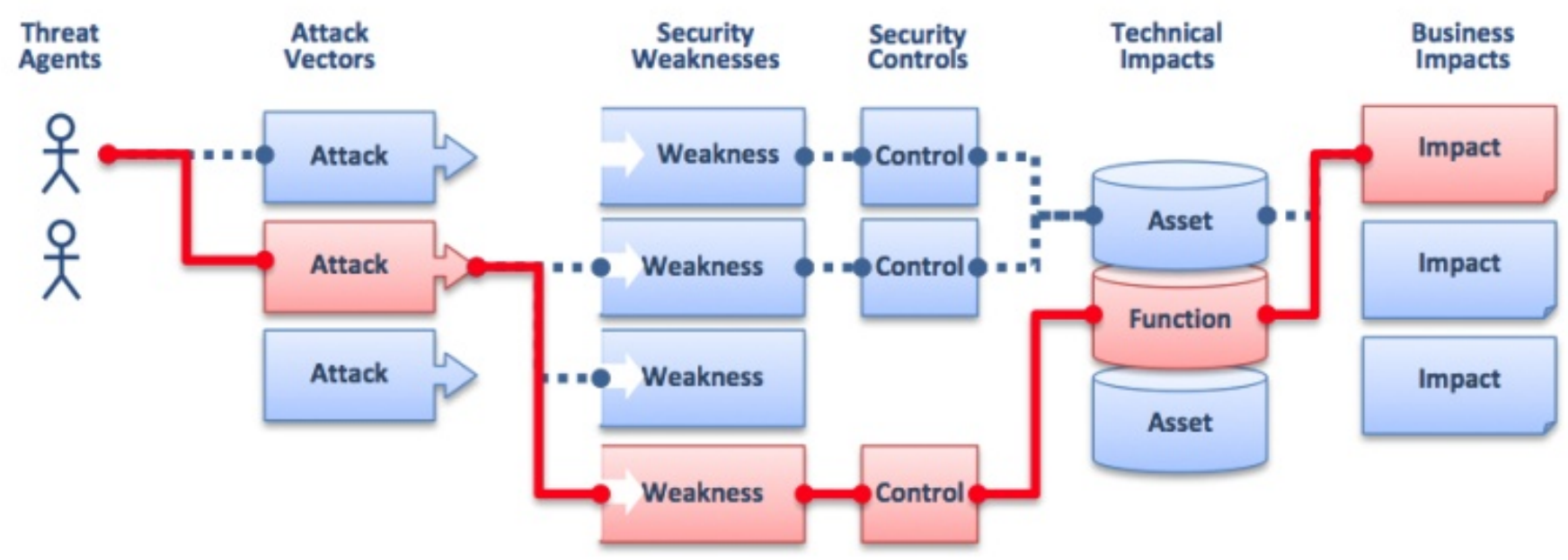

Figure 1. Information security risks, security controls, and impacts (Reprinted from OWASP, 2013: CC-BY-SA) 


\section{Information Security Best Practices: First Steps for Startups and SMEs}

\section{Urpo Kaila and Linus Nyman}

benefit is compliance with the General Data Protection Regulation (GDPR; eugdpr.org). The GDPR requires that companies who process personal data of persons from the EU perform impact assessments of the risk to the rights of the data subjects.

In addition to listing your risks in writing, we recommend that you also agree who in your company is in charge of each of the risks you have identified. When defining risk ownership, be mindful of previous workload and competence. If you have a limited amount of staff with existing skills in information security, offer other employees the opportunity to learn rather than by default making one IT-knowledgeable person the owner of all identified risks.

Some examples of common IT-related risks include:

- An account is compromised (e.g., a staff member's password is guessed or their credentials are phished more about this later).

- A service is not available. Whether it is a service that your company uses or a service that your company provides to your customers, a service not being available (when it should be) is an IT risk you should be aware of and plan for.
- Data is lost. Data loss could be accidental, a result of poor maintenance, or through malicious intent.

- A system is infected by viruses or other malware. These are the things many people closely associate with information security. They are most definitely an important consideration, but they are not the only consideration in putting together this list.

Table 1 shows a simple example of how you can list and manage your risks. Additional examples and guidelines can be found in the Recommended Reading section at the end of this article. In particular, we highlight the Risk Assessment Template by the WISE Community (wise-community.org/risk-assessment/).

\section{Protect Your Accounts, Critical Systems, Clouds, and Data}

The spectrum of risks to IT-related systems is broad. So, we will focus on a few topics of broad relevance as a starting point for implementing information security: accounts, critical systems, clouds, and data. A more comprehensive list of assets to protect, relevant to your specific company, should be derived from the list you drafted in Step 1.

Table 1. Example of a lightweight security framework for a startup or SME

\begin{tabular}{|c|c|c|c|c|c|c|c|}
\hline \multirow[b]{2}{*}{ Asset } & \multicolumn{3}{|c|}{ Risks } & \multirow[b]{2}{*}{ Risk Owner } & \multirow[b]{2}{*}{ Mitigation / Control } & \multirow[b]{2}{*}{$\begin{array}{l}\text { Reviewed } \\
\text { (Date/Initials) }\end{array}$} & \multirow[b]{2}{*}{$\begin{array}{l}\text { Review } \\
\text { Schedule }\end{array}$} \\
\hline & $\begin{array}{l}\text { Confidential } \\
\text { Information }\end{array}$ & Loss of Data & Service Down & & & & \\
\hline E-commerce portal & Medium & High & High & $\begin{array}{l}\text { Marketing } \\
\text { Manager }\end{array}$ & $\begin{array}{l}\text { Service Level Agreement } \\
\text { with fines, monitoring }\end{array}$ & Sep 18 N.N. & Annual \\
\hline$R \& D$ content & High & High & Medium & CTO & $\begin{array}{l}\text { Internal, mirrored server, } \\
\text { strong authentication }\end{array}$ & Aug 18 M.M. & Quarterly \\
\hline Customer database & High & High & Medium & Sales Manager & $\begin{array}{l}\text { Service Level Agreement } \\
\text { with fines }\end{array}$ & Nov 1 O.O. & Weekly \\
\hline HR database & High & Low & Low & HR Manager & Internal, mirrored server & & Daily \\
\hline Internal documents & High & Medium & Medium & CTO & $\begin{array}{l}\text { Internal, mirrored server, } \\
\text { strong authentication }\end{array}$ & & \\
\hline Contract database & Medium & Medium & Medium & Sales Manager & Backup with verified restore & & \\
\hline Financial services & Low & Low & Medium & $\mathrm{CFO}$ & Service Level Agreement & & \\
\hline CRM service & Medium & Medium & Medium & Sales Manager & $\begin{array}{l}\text { Service Level Agreement } \\
\text { with fines }\end{array}$ & & \\
\hline $\begin{array}{l}\text { Identify management } \\
\text { system }\end{array}$ & High & Medium & High & $\mathrm{CIO}$ & $\begin{array}{l}\text { Internal, mirrored server, } \\
\text { strong authentication }\end{array}$ & & \\
\hline
\end{tabular}

timreview.ca 


\section{Information Security Best Practices: First Steps for Startups and SMEs}

\section{Urpo Kaila and Linus Nyman}

Your goal here is to mitigate risk. Although the CIA triad of confidentiality, integrity, and availability, discussed in the previous section, offers a helpful way to think about and address information security issues, there are additional important tools to use in mitigating risk. These are called "controls". Controls can be divided up into three categories: preventative, detective, and responsive. Preventative controls seek to prevent unwanted things from happening. Detective controls help detect when unwanted things are happening. Responsive controls are controls that take effect after an unwanted incident has taken place; their goal is to help mitigate damage and get things back to normal.

Controls help mitigate risk but can themselves involve a balancing act. A concrete example, when deciding what controls to implement, is the balance between security and usability. Unfortunately, making something more secure often leads to it being less user-friendly, or at least somewhat more time-consuming to access or use. For example, implementing multi-factor authentication (something we will discuss shortly) makes an online account considerably more secure, but makes it take a while longer for the user to log in to their account.

\section{Protect your accounts}

Having an attacker gain control of an account can open up an organization to serious risk, particularly if the account in question has administrative rights. Think of it like losing your keys: the more keys on your keychain, the more access a thief will have if they get hold of them. An attacker can try to gain hold of an account by simply guessing a user's password. Or, they can try to gain access to an account by tricking the user into giving up this information - this is called "phishing". Important considerations in securing accounts are requiring strong passwords, educating employees about phishing and similar attacks, and - where possible-implementing multi-factor authentication:

1. Require strong passwords: Conventional wisdom regarding passwords has taught us that we can improve password strength by including a mixture of special characters, numbers, and a mixture of uppercase and lowercase letters. While such increased complexity is beneficial, password length is a more important consideration. In fact, password is in itself an unfortunate choice of word. It would be better to speak of passphrases, or "secret sentences" - the idea being that the most important goal of a password is to be long. Complexity is good, but its significance comes second to that of length. At a minimum, we recommend 12-character passwords. A good rule of thumb for a password is that it should be hard to guess but easy to remember. For example, "DogsDanceDiscoDaily" is both easier to remember and a stronger password than "p@s5w\#rd12". A second consideration regarding passwords is the importance of their being unique to an account. Reusing passwords is a common and very dangerous practice. The reason it is a huge risk is that data breaches have become common. If a password you reuse in multiple accounts is leaked online in a data breach, criminals can try this password on other accounts and potentially access an important work account even though the data breach was entirely unrelated to it. Default passwords (i.e., passwords or password patterns preset by a device manufacturer) are equally a risk and should be changed when possible. Such passwords can often either be easy to guess or can be found online. Both commonly used passwords as well as default passwords can be expected to be included in toolkit dictionaries, which are huge lists of commonly used passwords that criminals can use to attempt to break into accounts.

\section{Learn to recognize phishing and other common} cons: Another common attack is to try to trick a user into giving up login information or other sensitive data through phishing. Sites are made to look identical to trusted sites, with the goal of tricking users into handing over to the criminals their login information, credit card number, or other sensitive data. Another example of a popular scam is the CEO scam, in which criminals trick a company employee to pay a bogus invoice by attaching it to an email made to look like it is from the CEO. Artificial intelligence can detect many forms of phishing and scams, but not all. Email sender information is easy to spoof, meaning it is trivial to make an email look as though it was sent by someone else. Links can be made to look like they lead to a real site but actually lead to a phishing site. And only the URL of a website - not what the site looks like - actually tells you where you are. It is very important for all employees to have a basic grasp of such tricks and how to spot them.

3. Implement multi-factor authentication: Another good way to secure accounts is to implement multifactor authentication, sometimes known as twofactor authentication or 2FA. This means that, in addition to a password, you will also need to authenticate yourself through a second means, or factor. This can be, for instance, a USB dongle or through a key (password) sent to your cellphone. Therefore, if a criminal manages to guess or phish a password to an 


\section{Information Security Best Practices: First Steps for Startups and SMEs}

\section{Urpo Kaila and Linus Nyman}

account, you can still be safe as long as they cannot access your second factor.

Box 1 lists examples of actions to take and controls to implement to protect accounts.

\section{Protect your critical systems}

Here, it is useful to distinguish between systems, data, and services. For example, you can have a computer or a corresponding virtual machine, files containing data, and a running service for processing customer orders. A laptop in and of itself is not mission critical. However, mission-critical data might exist solely on one laptop, which is not advisable at all security-wise.

Common critical IT systems to most business are the invoicing, sales, logistics, or customer management systems and all the data they contain. Also, be mindful of whether any of your mission-critical IT systems rely on so-called legacy systems, meaning outdated hardware or software. An additional consideration in identifying risks and devising security is being aware of whether any of these systems are such that only one or a few people know how they work. Is there a critical function that ceases to function when any one single person is no longer there to manage it?

Box 2 lists examples of actions to take and controls to implement to protect critical systems.

\section{Protect your cloud}

Companies are becoming increasingly reliant on cloud providers for their data storage. Make sure you have written agreements with all your cloud providers. Before committing to a provider, always check the cloud provider's rights and responsibilities. Some important considerations are: What do they do to safeguard your data? What happens if they lose your data? It could be that they will have to pay a fine if they lose your data, but that will be little consolation to you if business-critical information goes missing. Also, check their promised availability. Availability refers to how reliably their service is accessible, and is commonly measured in nines (i.e., "How many 9s?"): 90\% availability is considered one nine. This would translate to 36.5 days of downtime per year. So, $99 \%$ is two nines, $99.9 \%$ is three nines, etc. A guarantee of six nines means, at most, half a minute of downtime per year. Estimate the value/risk to your business of cloud downtime and choose accordingly.

If you are a small or medium-sized company, it probably is not worth your time to even imagine that you could negotiate a unique and favourable deal for yourself with
Box 1. Practical actions to protect accounts

- Have minimum requirements for password length. For example, require all passwords to have at least 12 characters.

- Implement multi-factor authentication, at least on email and other critical accounts.

- Only those who need accounts should have them. Be mindful of test accounts - make them as secure as other accounts (e.g., with strong passwords) and delete them once they have served their purpose.

- Implement mandatory information security training for all employees (e.g., to teach them how to recognize phishing and other scams).

- Remove accounts when no longer needed.

- Restrict rights on accounts to what is needed.

Box 2. Practical actions to protect critical systems

- Ensure that you install security patches in a timely manner.

- Shut down all unnecessary services on your hosts. For example, shut down a local email service if you do not need it.

- Do not make your mission-critical infrastructure directly available on a public network.

- Implement layered defence. For example, do not expose confidential information directly to public networks.

- Ensure that all accounts are unique and can be connected to a person. Do not share accounts.

- Authenticate all users. Everybody must log in with a password or with a key.

- Log access and keep your logs on a separate host.

- Restrict network access with firewall rules, both on the network level and on host or service levels 


\section{Information Security Best Practices: First Steps for Startups and SMEs}

\section{Urpo Kaila and Linus Nyman}

the likes of Microsoft or Amazon. But even then, do make sure any deal you get from them is sufficiently favourable (e.g., ask "How many 9s?") and actually read the agreement and know what you are getting. If you are looking into buying a service from a smaller company, check not only your rights and the supplier's rights and responsibilities but also the supplier's accreditations. The ISO/IEC 27001 certification for information security management systems is the most valued international certification, and all serious cloud providers have been awarded this certification.

Box 3 lists examples of actions to take and controls to implement to protect cloud-based assets.

\section{Protect your data}

Here, it is useful to circle back to the original point of Step 1: before we can secure something, we must know what we want to secure. Unfortunately, with young companies, a lack of knowledge about their data - what exactly it is and where it is located - is quite common. For example, personal and corporate email accounts may be used interchangeably, and things like orders, invoices, and commitments may be distributed among them. Companies should try to keep personal and private accounts separated. If you always have to start by searching your email to find what data you are looking for, you - and your company's information security - would benefit from better structuring.

Whether your data is in the cloud or on your own hard drives, one cannot overstate the importance of backups and the ability to recover from anything - from ransomware to a hard drive failure or a fire. A crucial but often overlooked step is testing your backup system to make sure things work in practice, not just in theory. You can further improve your information security by encrypting data before uploading it to the cloud.

Box 4 lists examples of actions to take and controls to implement to protect data.

\section{Make a Continuity Plan}

Even after taking significant steps to ensure things do not go wrong, it is still important to have in place a disaster recovery plan prepared in advance for when things, despite your best efforts, go wrong anyway. This step ties in with the previous step on protecting your various assets by addressing what to do if those protections fail. Making a continuity plan can be perhaps the most effective way to communicate information security in practice to your staff and other stakeholders, as it
Box 3. Practical actions to protect cloud-based assets

- Check what your provider promises you on security.

- Marketing materials are not enough - you should require security agreements.

- Make sure your providers have solid privacy policies.

- Check what guarantees are provided on the availability of the service and of your data.

Box 4. Practical actions to protect data

-Write down what critical data you need to be able to restore to recover your business.

- Have an automatic backup system in place.

- Test the backup system regularly, for example weekly, to ensure that the data really is being backed up and can be successfully restored.

- Check the integrity of your files and databases, too. Can you actually read what is restored?

- Mark and classify your data and your property. Write "confidential" or "internal" if the file is not public.

- Write a security policy for your staff. Company systems are intended only for business use; inappropriate use and abuse or causing harm is prohibited.

can make the abstract controls understandable for people with less or no knowledge of the affected system or the incident that might have affected it.

A continuity plan can be implemented in different ways. The basic concept is to secure your business operations even in the case of various disturbances or unfortunate events. One approach is to have a set of controls in place. This could be lists of fallback options, as the example in Table 2 shows. This example for a business continuity plan shows a concise, simple template for writing your contingency plan, which is based on a 


\section{Information Security Best Practices: First Steps for Startups and SMEs}

\section{Urpo Kaila and Linus Nyman}

version in use at the Finnish IT Center for Science (CSC). The template in Table 2 gives a sense of the recommended level of granularity for a continuity plan. However, an actual plan would be less generic and should include specific services and the names of the individuals responsible for them. So, should something happen to a given critical function, you would have a "plan B" in place to provide that function. Or, if data is lost, you would have a recovery plan ready, describing how to recover that data. Also, for critical services, it is good to have a disaster strategy. If the customer portal is down, it would be good to at least be able to redirect traffic to another site, saying that the service is temporarily down but recovery is under way.

\section{Monitor and Review}

This is an important yet often overlooked part of a company's information security. Even with the best of plans in place and the most advanced of security products securing your systems, it is still important to continuously monitor and review the situation. This may be challenging for a small company to do continuously, but you should try to have at least some security-related metrics that you keep track of, which can give you some insight into the situation and its trends or evolution over time. Some examples of parameters for security metrics could be service availability ("How many 9s?"), the amount of malware detected, security events and security incidents, and the number of security agreements you have signed.

Monitoring is also useful as far as compliance is concerned: the data you have gathered is something to mention, or show, should you be asked about your company's insights into its own information security. An additional benefit of monitoring is that having logs is crucial in the event of a compromised system. Without logs, you will be left guessing what went wrong and why. Your logs will not only enable uncovering what happened, but it will also inform your decision regarding how to respond to an incident.

There are many other things that would be useful to monitor and examine, but which may require more familiarity with information security - and in particular computers and networks - than people in your company may have. A further important action, particularly if in-house knowledge is limited, is to have an expert from outside of one's company examine your security. They can be hired to instruct you regarding how to secure your systems as well as to test your product, company, or network for vulnerabilities.
Table 2. Example of a concise business continuity plan

\section{Business Continuity Plan for Service X}

1. Purpose and scope of the plan

2. Description of Service X

2.1 Description

2.2 Network diagram

2.3 System components

2.4 Dependencies (of other services and to other services)

3. Contact information

3.1 Administrative staff

3.2 Customers and other stakeholders

3.3 Subcontractors and agreements

4. Risk and impact analysis

4.1 Risk analysis

4.2 List of related security controls

5. Incident management guideline

5.1 Roles

5.2 Crisis communication

5.3 Contact with authorities and CSIRT teams

6. Disaster recovery plan 


\section{Information Security Best Practices: First Steps for Startups and SMEs}

\section{Urpo Kaila and Linus Nyman}

\section{Conclusions}

Information security is about knowing what to protect and how to protect it. If you understand your company and what value you offer to your clients, then you have already taken an important first step towards implementing information security. Rather than feeling intimidated by the breadth or complexity of the myriad potential weaknesses or vulnerabilities your company or its IT system is facing, focus instead on the concrete tasks involved in outlining a plan for how to protect your business and the data of your customers and your staff. Then implement that plan. If, or rather when, you face a security incident, remember: don't panic. Stick with the security framework you have tailored for your own company and face the threats. During the incident, you can then, as the United States marines slogan says: "improvise, adapt, and overcome".

When you have created a minimum feasible security model for your services and your systems you should advance to continuously improve your security by balancing risks and the costs in money, time, and usability of available security controls. You could, for example, consider deploying controls for proactive intrusion detection and prevention (IDS/IDP), identifying advanced persistent threats (APT), or evasions of your firewall rules. Many of these functions can also be obtained from a service provider.

Adequately managed information security is part of the basic governance of any business, and it is also a good and necessary investment. In addition to mitigating your risks, you also need security to show compliance. Should things go wrong, you have at least made a reasonable effort to protect your business and the data of your customers and your staff. It is also a good idea to have somebody else to review your security. A focused network scan for vulnerabilities, penetration testing of your critical services, or a walkthrough on how you make changes in your services (change management) can help you to identify issues and patch vulnerabilities before a malicious party finds them. Proactive security is also a very good way to show due diligence in security matters. However, no control is bulletproof, especially when considering potential trade-offs with usability and the need to keep costs at a reasonable level.
But you need to begin with the basics first. If you follow the basic steps we have presented in this introductory article, you are already well on your way to ensuring adequate information security for your business. Starting with best practices when you are small and growing them as you grow is an excellent way to implement and maintain information security practices. The steps we have outlined here are important, but they are just the beginning. Once you feel you have understood and implemented them, please dive deeper into the topic. As your company and your understanding of information security principles grow, you may also decide to adopt more comprehensive frameworks, as highlighted in the recommended reading list below.

\section{Recommended Reading}

- 10 Steps to Cyber Security (UK National Cyber Security Centre)

https://www.ncsc.gov.uk/guidance/10-steps-cyber-security

- OWASP Top 10 Most Critical Web Application Security Risks (Open Web Application Security Project) https://www.owasp.org/index.php/Category:OWASP_Top_Ten_ Project

- NIST Special Publication 800-Series (US National Institute of Standards and Technology)

https://www.nist.gov/itl/nist-special-publication-800-series-generalinformation

- Security for Collaborating Infrastructures Trust Framework (WISE Community)

https://wise-community.org/sci/

- Risk Assessment (WISE Community)

https://wise-community.org/risk-assessment/

- Cybersecurity Best Practices (Center for Internet Security) https://www.cisecurity.org/cybersecurity-best-practices/

- Carry On: Sound Advice from Schneier on Security (Bruce Schneier)

https://www.schneier.com/books/carry_on/ 


\section{Information Security Best Practices: First Steps for Startups and SMEs}

\section{Urpo Kaila and Linus Nyman}

\section{About the Authors}

Urpo Kaila is the Head of Security for CSC - the Finnish IT Center for Science. His background in the information security industry, with long experience in handling security incidents as well as developing solutions for information security and data protection. He has been responsible to achieve the valued ISO/IEC 27001 information security management certification for CSC and is a steering committee member in security groups for some European Research Infrastructures, such as WISE and GÉANT SIG-ISM. Urpo holds the professional international information security certificates CISSP, GCIH, GCED, CISM, and ISO 27001 Lead Auditor. He also holds a Master's degree from the Hanken School of Economics. His research focuses on best practices in information security and data protection.

Linus Nyman is an Assistant Professor at the Hanken School of Economics in Helsinki, Finland, and an Adjunct Research Professor in the Technology Innovation Management (TIM) program at Carleton University in Ottawa, Canada. He has lectured on a range of topics, including information security and privacy, information systems science, corporate strategy, and open source software development. His current research focuses on information security and privacy, which are topics he also covers in a blog for the Finnish daily newspaper HBL. Linus holds a $\mathrm{PhD}$ and a Master's degree, both from the Hanken School of Economics.

\section{References}

Burton, G. 2017. NotPetya Is, er, Not Ransomware, Victims Unlikely to Get Files Back. The Inquirer, June 29, 2017. Accessed October 22, 2018:

https://www.theinquirer.net/inquirer/news/3012890/notpetyaransomware-intended-to-destroy-not-extort-money

Europol. 2017a. 2017, The Year When Cybercrime Hit Close to Home. Press release. The Hague, Netherlands: European Union Agency for Law Enforcement Cooperation (Europol), September 27, 2017. Accessed October 22, 2018:

https://www.europol.europa.eu/newsroom/news/2017-yearwhen-cybercrime-hit-close-to-home

Europol. 2017b. Internet Organized Crime Assessment (IOCTA) 2017 Report. The Hague, Netherlands: European Cybercrime Centre; European Union Agency for Law Enforcement Cooperation (Europol). Accessed October 22, 2018:

https://www.europol.europa.eu/iocta/2017/index.html
Hypponen, M., \& Nyman, L. 2017. The Internet of (Vulnerable) Things: On Hypponen's Law, Security Engineering, and IoT Legislation. Technology Innovation Management Review, 7(4): $5-11$.

http://doi.org/10.22215/timreview/1066

ISO. 2013. ISO/IEC 27001:2013, Information technology - Security techniques - Information security management systems Requirements. Geneva: International Organization for Standardization (ISO).

https://www.iso.org/standard/54534.html

Kaila, U., Passerini, M., \& Virtanen, J. 2011. Metrics and Best Practices for Host-based Access Control to Ensure System Integrity and Availability. In Proceedings of the Cray User Group Conference (CUG 2011), May 23-26, 2011, Fairbanks, Alaska. https://cug.org/5publications/proceedings_attendee_lists/CUG11CD/pages/1program/final_program/10.monday.html

Kaspersky Lab. 2017. Kaspersky Security Bulletin: Overall Statistics for 2017. Kaspersky Lab, December 14, 2017. Accessed October 22, 2018:

https://securelist.com/ksb-overall-statistics-2017/83453/

Mathews, L. 2017. The NotPetya Ransomware May Actually Be A Devastating Cyberweapon. Forbes, June 30. Accessed October 22, 2018:

https://www.forbes.com/sites/leemathews/2017/06/30/thenotpetya-ransomware-may-actually-be-a-devastatingcyberweapon/

NIST. 2018a. Cybersecurity Framework. National Institute of Standards and Technology (NIST), April, 2018. Accessed November 1, 2018:

https://www.nist.gov/cyberframework

NIST. 2018b. NIST Special Publication 800-Series General Information. National Institute of Standards and Technology (NIST), May 21, 2018. Accessed November 1, 2018: https://www.nist.gov/itl/nist-special-publication-800-seriesgeneral-information

Novet, J. 2017 Shipping Company Maersk Says June Cyberattack Could Cost It Up to $\$ 300$ million. CNBC, August 16, 2017. Accessed October 22, 2018:

https://www.cnbc.com/2017/08/16/maersk-says-notpetyacyberattack-could-cost-300-million.html

Oath. 2017. Yahoo Provides Notice to Additional Users Affected by Previously Disclosed 2013 Data Theft. Press release. Oath, October 3, 2017. Accessed October 22, 2018:

https://www.oath.com/press/yahoo-provides-notice-toadditional-users-affected-by-previously/

OWASP. 2013. CISO AppSec Guide: Criteria for Managing Application Security Risks. Open Web Application Security Project (OWASP), September 18, 2013. Accessed October 22, 2018: https://www.owasp.org/index.php/CISO_AppSec_Guide:_Criteria _for_Managing_Application_Security_Risks

OWASP. 2015. OWASP Security Knowledge Framework. Open Web Application Security Project (OWASP), September, March 11, 2015. Accessed October 22, 2018: https://www.owasp.org/index.php/OWASP_Security_Knowledge_ Framework

Rees, J. 2010 Information Security for Small and Medium-Sized Business. Computer Fraud \& Security, 2010(9): 18-19. https://doi.org/10.1016/S1361-3723(10)70123-8 


\section{Information Security Best Practices: First Steps for Startups and SMEs}

\section{Urpo Kaila and Linus Nyman}

Renaud, K. 2016. How Smaller Businesses Struggle with Security Advice. Computer Fraud \& Security, 2016(8): 10-18.

https://doi.org/10.1016/S1361-3723(16)30062-8

Thomson, I. 2017. NotPetya Ransomware Attack Cost Us $\$ 300 \mathrm{~m}-$ Shipping Giant Maersk. The Register, August 16, 2017. Accessed October 22, 2018:

https://www.theregister.co.uk/2017/08/16/notpetya_ransomware _attack_cost_us_300m_says_shipping_giant_maersk/

Webroot. 2017. Quarterly Threat Trends. Webroot, September 2017. Accessed October 22, 2018:

https://www.webroot.com/us/en/business/resources/threattrends/sept-2017

Whitten, A., \& Tygar J. D. 1996. Why Johnny Can't Encrypt: A Usability Evaluation of PGP 5.0. In Proceedings of the 8th USENIX Security Symposium: 169-184. August 23-36, 1999. Washington, DC.

https://www.usenix.org/legacy/events/sec99/full_papers/whitten /whitten_html/index.html

Williams-Grut, O. 2018. Hackers Once Stole a Casino's High-Roller Database Through a Thermometer in the Lobby Fish Tank. Business Insider, April 15, 2018. Accessed October 22, 2018:

https://www.businessinsider

Citation: Kaila, U., \& Nyman, L. 2018. Information Security Best Practices: First Steps for Startups and SMEs. Technology Innovation Management Review, 8(11): 32-42. http://doi.org/10.22215/timreview/1198

Keywords: information security, cybersecurity, best practices, startups, SMEs, risk management 


\section{Author Guidelines}

These guidelines should assist in the process of translating your expertise into a focused article that adds to the knowledge resources available through the Technology Innovation Management Review. Prior to writing an article, we recommend that you contact the Editor to discuss your article topic, the author guidelines, upcoming editorial themes, and the submission process: timreview.ca/contact

\section{Topic}

Start by asking yourself:

- Does my research or experience provide any new insights or perspectives?

- Do I often find myself having to explain this topic when I meet people as they are unaware of its relevance?

- Do I believe that I could have saved myself time, money, and frustration if someone had explained to me the issues surrounding this topic?

- Am I constantly correcting misconceptions regarding this topic?

- Am I considered to be an expert in this field? For example, do I present my research or experience at conferences?

If your answer is "yes" to any of these questions, your topic is likely of interest to readers of the TIM Review.

When writing your article, keep the following points in mind:

- Emphasize the practical application of your insights or research.

- Thoroughly examine the topic; don't leave the reader wishing for more.

- Know your central theme and stick to it.

- Demonstrate your depth of understanding for the topic, and that you have considered its benefits, possible outcomes, and applicability.

- Write in a formal, analytical style. Third-person voice is recommended; first-person voice may also be acceptable depending on the perspective of your article.

\section{Format}

1. Use an article template: .doc .odt

2. Indicate if your submission has been previously published elsewhere. This is to ensure that we don't infringe upon another publisher's copyright policy.

3. Do not send articles shorter than 2000 words or longer than 5000 words.

4. Begin with a thought-provoking quotation that matches the spirit of the article. Research the source of your quotation in order to provide proper attribution.

5. Include a 2-3 paragraph abstract that provides the key messages you will be presenting in the article.

6. Provide a 2-3 paragraph conclusion that summarizes the article's main points and leaves the reader with the most important messages.

7. Include a 75-150 word biography.

8. List the references at the end of the article.

9. If there are any texts that would be of particular interest to readers, include their full title and URL in a "Recommended Reading" section.

10. Include 5 keywords for the article's metadata to assist search engines in finding your article.

11. Include any figures at the appropriate locations in the article, but also send separate graphic files at maximum resolution available for each figure. 


\section{Issue Sponsor}

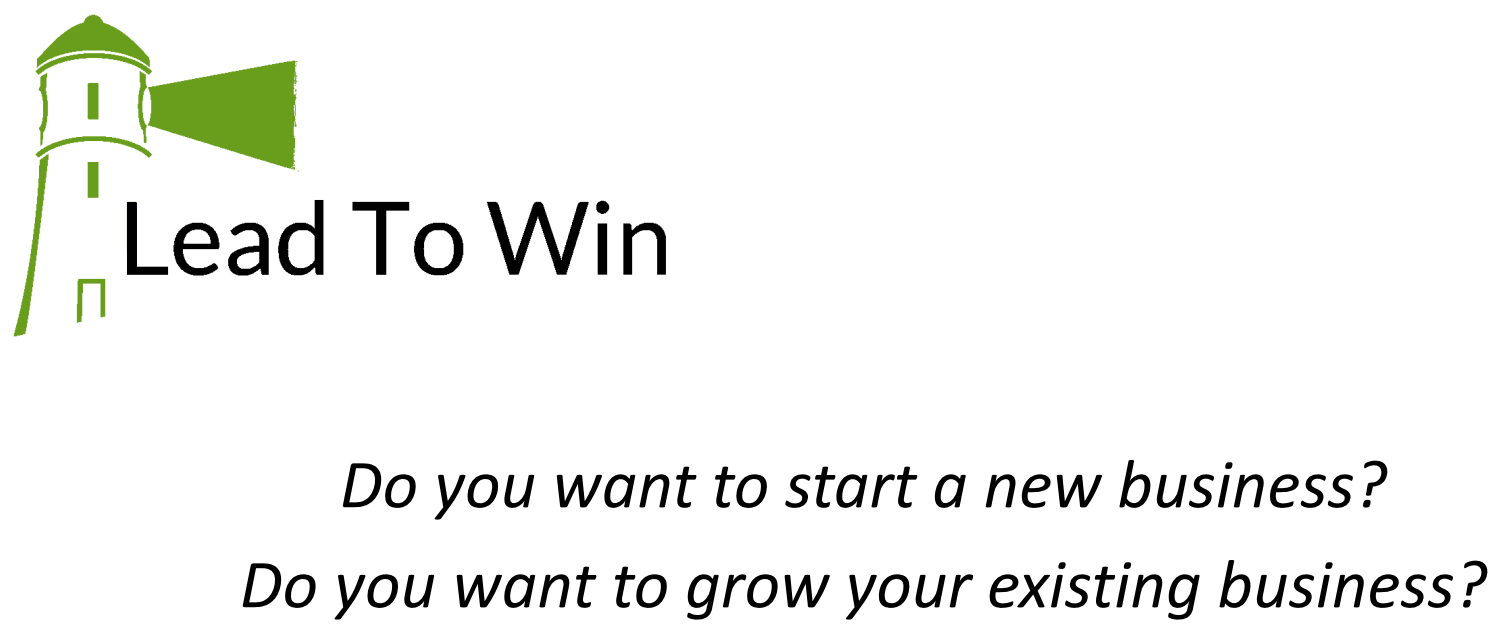

Lead To Win is a free business-development program to help establish and grow businesses in Canada's Capital Region.

Benefits to company founders:

- Knowledge to establish and grow a successful businesses

- Confidence, encouragement, and motivation to succeed

- Stronger business opportunity quickly

- Foundation to sell to first customers, raise funds, and attract talent

- Access to large and diverse business network

\section{Apply Now}

* Twitter

f Facebook

in Linkedin

E Eventbrite

9 Slideshare

- YouTube

- Flickr 


\section{Academic Affiliations and Funding Acknowledgements}

Canadà
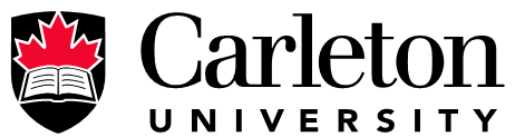

U N I V E R S I T Y

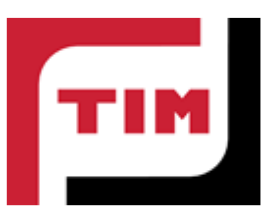

The Federal Economic Development Agency for Southern Ontario (FedDev Ontario; feddevontario.gc.ca) is part of the Innovation, Science and Economic Development portfolio and one of six regional development agencies, each of which helps to address key economic challenges by providing regionallytailored programs, services, knowledge and expertise.

- The TIM Review receives partial funding from FedDev Ontario's Investing in Regional Diversification initiative.

Technology Innovation Management (TIM; timprogram.ca) is an international master's level program at Carleton University in Ottawa, Canada. It leads to a Master of Applied Science (M.A.Sc.) degree, a Master of Engineering (M.Eng.) degree, or a Master of Entrepreneurship (M.Ent.) degree. The objective of this program is to train aspiring entrepreneurs on creating wealth at the early stages of company or opportunity lifecycles.

- The TIM Review is published in association with and receives partial funding from the TIM program. 